\title{
Transcriptomics of Epichloë-Grass Symbioses in Host Vegetative and Reproductive Stages
}

\author{
Padmaja Nagabhyru, ${ }^{1}$ Randy D. Dinkins, ${ }^{2}$ and Christopher L. SchardI ${ }^{1,+}$ \\ ${ }^{1}$ Department of Plant Pathology, University of Kentucky, Lexington, KY 40546, U.S.A.; and ${ }^{2}$ USDA-ARS, Forage-Animal \\ Production Research Unit, Lexington, KY 40546, U.S.A.
}

Accepted 20 July 2018.

\begin{abstract}
Epichlö species are fungal symbionts (endophytes) of coolseason grasses that transmit vertically via inflorescence primordia (IP), ovaries (OV), and ultimately, embryos. Epichlö̈ coenophiala, an endophyte of tall fescue (Schedonorus arundinaceus), provides multiple protective benefits to the grass. We conducted transcriptome analysis of the tall fescue-E. coenophiala symbiosis, comparing IP, OV, vegetative pseudostems (PS), and the lemma and palea (LP) (bracts) of the young floret. Transcriptomes of host OV and PS exhibited almost no significant differences attributable to endophyte presence or absence. Comparison of endophyte gene expression in different plant parts revealed numerous differentially expressed genes (DEGs). The 150 endophyte DEGs significantly higher in PS over OV included genes for alkaloid biosynthesis and sugar or amino acid transport. The 277 endophyte DEGs significantly higher in OV over PS included genes for protein chaperones (including most heat-shock proteins), trehalose synthesis complex, a bax inhibitor1 protein homolog, the CLC chloride ion channel, catalase, and superoxide dismutase. Similar trends were apparent in the Brachypodium sylvaticum-Epichlö sylvatica symbiosis. Gene expression profiles in tall fescue IP and LP indicated that the endophyte transcriptome shift began early in host floral development. We discuss possible roles of the endophyte DEGs in colonization of reproductive grass tissues.
\end{abstract}

Grass-symbiotic fungi of genus Epichlö and the alkaloids they produce have been extensively researched because of their various benefits and detriments in ecological and agricultural contexts. Benefits to the hosts include enhanced tolerances of drought, osmotic and heat stresses, increased resistance to insects

Sequence data have been deposited in the National Center for Biotechnology Information (NCBI) GenBank database under accession numbers MH174940 to MH174944 and MH178124 to MH178233. NCBI SRA accessions are SRP135865 for RNA-seq data from tall fescue-Epichlö coenophiala symbioses, SRP136339 for DNA-seq data for the same symbioses, and SRP136110 for RNA-seq data from the Brachypodium sylvaticum-Epichloë sylvatica symbiosis.

${ }^{\dagger}$ Corresponding author: Christopher L. Schardl; E-mail: schardl@uky.edu

Funding: This work is supported by the U.S. Department of Agriculture Special Cooperative Agreement grant 2016-020508441 and National Institute of Food and Agriculture Hatch project KY012044.

*The $\boldsymbol{e}$-Xtra logo stands for "electronic extra" and indicates that five supplementary figures and 12 supplementary datasets are published online.

This article is in the public domain and not copyrightable. It may be freely reprinted with customary crediting of the source. The American Phytopathological Society, 2019. and nematodes, and improved acquisition and utilization of mineral nutrients (Assuero et al. 2006; Bacetty et al. 2009; Elbersen and West 1996; Elmi and West 1995; Elmi et al. 2000; Lyons et al. 1990; Malinowski and Belesky 1999, 2000; Timper et al. 2005). However, livestock that graze some of these endophyte-symbiotic grasses can suffer toxicoses due to indolediterpene or ergot alkaloids produced by the endophytes (Schardl et al. 2013a).

The symbiotic system comprising the grass tall fescue, Schedonorus arundinaceus $=$ Lolium arundinaceum, with its seed-borne endophyte, Epichloë coenophiala, is one of the most extensively studied because of its economic importance worldwide (Bouton et al. 2002; Hoveland 2009; Hume and Sewell 2014). This is also an extraordinarily stable, systemic, and mutualistic symbiosis in which the endophyte colonizes both vegetative and reproductive parts of tall fescue (Zhang et al. 2017). Similar to other Epichlö̈ species in cool-season grasses (Christensen et al. 2008; Tanaka et al. 2012), E. coenophiala is a systemic symbiont throughout the plant lifecycle, exhibiting in-planta growth that is controlled and synchronized with growth and development of its host. Aboveground organs that are most heavily colonized include the pseudostems (PS), regions around vegetative and floral meristems, host ovaries (OV), and developing seeds (Hinton and Bacon 1985; Zhang et al. 2017).

A key aspect of symbiotic Epichlö species is their vertical transmission in a process that causes no harm to any of the plant reproductive parts, leading to highly efficient maternal-line transmission through successive host generations (Hinton and Bacon 1985; Zhang et al. 2017). Most Epichlö̈-symbiotic grasses produce asymptomatic inflorescences, which produce normal seeds with viable hyphae of the symbiont. The fungus is thereby transmitted to each successive generation of host plants. This is the only apparent transmission mechanism for E. coenophiala, the common endophyte of northern European and some Mediterranean ecotypes of tall fescue used in most cultivars worldwide (Ekanayake et al. 2012; Young et al. 2014).

Many seed-transmitted Epichlö $\ddot{e}$ species are interspecific hybrids (Moon et al. 2004), though E. coenophiala is unusual in that it has three sexual ancestors, Epichloë festucae, Epichlö typhina subsp. poae, and an unidentified species belonging to the Lolium-associated endophyte (LAE) clade of Epichlö̈ (Tsai et al. 1994). The ancestral species have a sexual life history culminating in contagious ascospores that mediate horizontal transmission (Chung and Schardl 1997), which should facilitate coinfections of plants or seeds as a prelude to interspecific hybridization. In contrast, hybrid Epichlö̈ species are almost invariably asexual and strictly seed-borne (Moon et al. 2004). In the case of E. coenophiala in tall fescue cultivar Kentucky 31 and related cultivars, seed transmission is extremely high, with $96 \%$ 
or more of seed progeny bearing viable endophyte (Bouton et al. 2002; Florea et al. 2016).

Over the past century, microscopic studies have been conducted on growth and colonization of host reproductive parts by Epichloë occultans in Lolium temulentum (Freeman 1904) and Lolium multiflorum (Sugawara et al. 2004), Epichloë festucae vars. lolii and festucae in Lolium perenne (Card et al. 2013; Liu et al. 2017; Majewska-Sawka and Nakashima 2004; Philipson and Christey 1986), and E. coenophiala in tall fescue (Card et al. 2013; White et al. 1991; Zhang et al. 2017). In each case, association with the shoot primordia prepositions the endophyte to colonize the inflorescence primordia (IP) after vernalization. In the vegetative state, each plant has several tillers that arise from its basal crown (Supplementary Fig. S1). Each tiller is composed of multiple leaves, which have differentiated portions that include basal sheaths, a collar and ligular zone, and the apical blade. The lower portion of each tiller comprises several leaf sheaths concentrically arranged to form the PS, which is the vegetative part where E. coenophiala is most concentrated (Hinton and Bacon 1985). After overwinter vernalization, the shoot apical meristem differentiates into an IP, which proceeds to give rise to an inflorescence with multiple spikelets, each with multiple florets. Fertile florets have both the female style and male anthers, flanked by two bracts called the lemma and palea (LP). In grass-Epichlö̈ symbioses, fungal hyphae are reported to be absent from pollen but present in preanthesis OV, including ovules (Zhang et al. 2017).

In tall fescue, which is an outcrossing species, pollination requires anther exsertion at anthesis. After pollination, the fungus enters and grows in the developing seed until, in the mature seed, it is abundant in and above the aleurone layer and, also, present in the embryonic axis, including the embryonic leaves. Upon germination, the endophyte grows in shoot primordia and thus transmits into tillers (Freeman 1904).

Though several aspects of grass-Epichlö symbioses have received intensive study, including several recent transcriptomic investigations of cross-talk in vegetative plant parts (Dinkins et al. 2017; Dupont et al. 2015; Eaton et al. 2015; Schmid et al. 2017), there has been no research to date into how the fungus and plant respond to each other at the molecular level as the fungus colonizes plant reproductive parts. Therefore, we conducted high-throughput messenger RNA (mRNA) sequencing (RNA-seq) of various tall fescue parts to investigate transcriptome changes in the host induced by the endophyte as well as transcriptome changes in the endophyte as it systemically colonizes the developing vegetative and reproductive parts of the plant, thereby elucidating the genes and pathways that may be involved in this important process of hereditary symbiosis.

\section{RESULTS}

Endophyte transcription levels in symbio.

We investigated E. coenophiala gene expression profiles in four plant parts from endophyte-symbiotic $(\mathrm{E}+)$ tall fescue plants: PS, IP (distinguished as young and small [IP-s] or slightly older and larger [IP-1]), OV, and the LP. The average number of RNA-seq reads mapping to the E. coenophiala e19 genome as a proportion of total reads was much higher in PS and LP compared with OV and IP, for example, fourfold higher in PS than in OV (Table 1). To determine whether these differences may be due to differences in endophyte abundance, we conducted high-throughput DNA sequence (DNA-seq) analysis of OV, LP, and PS parts from the same four E+ plants. The plant parts were collected at the same time from the same plants and were of similar developmental age as the material used for RNAseq. We quantified DNA-seq reads mapping to the E. coenophiala genome relative to total DNA-seq reads in each sample (Table 2). By this approach, estimated relative abundances of endophyte in different plant parts were PS $>$ LP $>$ OV (Table 2). For each plant part, we then calculated the ratio of the proportion of RNA-seq reads (Table 1) to the proportion of DNA-seq reads (Table 2) that mapped to the E. coenophiala genome. These ratios differed significantly between parts, up to sevenfold, with LP > OV > PS (Table 2). Therefore, the relatively low proportion of fungal transcripts in OV and LP compared with PS was not indicative of lower gene expression in the floral parts but, instead, reflected much lower endophyte abundance in OV and LP. The average level of E. coenophiala gene expression was actually much lower in PS than in the other plant parts.

\section{Endophyte gene expression profiles categorized by k-means cluster analysis.}

The E. coenophiala genome assemblies (Florea et al. 2016; Schardl et al. 2013b) were annotated with MAKER (Cantarel et al. 2008), using evidence of inferred protein sequences from Epichloë festucae E2368 gene models (Schardl et al. 2013c), to

Table 1. Fungal copy DNA (cDNA of messenger RNA) reads from endophyte-symbiotic plant parts

\begin{tabular}{|c|c|c|c|c|c|c|}
\hline \multirow[b]{2}{*}{ Sample } & \multirow[b]{2}{*}{$n$} & \multirow[b]{2}{*}{ RNA-seq reads ${ }^{a}$} & \multicolumn{2}{|c|}{ Epichlö̈ coenophiala ${ }^{\mathbf{b}}$} & \multicolumn{2}{|c|}{ Tall fescue assembly TF153K } \\
\hline & & & No. mapped & $\%$ Reads & No. mapped & $\%$ Reads \\
\hline Ovary & 4 & $180,054,665$ & 465,318 & $0.26 \pm 0.03$ & $149,597,656$ & $83 \pm 0.17$ \\
\hline Pseudostem & 4 & $266,615,615$ & $2,808,596$ & $1.05 \pm 0.58$ & $217,435,323$ & $82 \pm 0.57$ \\
\hline Lemma and palea & 4 & $177,955,655$ & $1,909,850$ & $1.07 \pm 0.36$ & $135,348,748$ & $76 \pm 0.68$ \\
\hline Small inflorescence primordia & 3 & $123,245,841$ & 201,438 & $0.16 \pm 0.03$ & $101,518,358$ & $82 \pm 1.80$ \\
\hline Large inflorescence primordia & 4 & $158,493,099$ & 216,513 & $0.14 \pm 0.03$ & $133,340,101$ & $84 \pm 0.38$ \\
\hline
\end{tabular}

a Total number of RNA-seq reads after filtering out low-quality reads.

b The number mapped to the E. coenophiala e19 genome and average percentage of RNA-seq reads mapped to E. coenophiala \pm standard error (SE).

${ }^{c}$ Number mapped to tall fescue assembly TF153K and average percentage of reads mapped to tall fescue assembly \pm SE.

Table 2. Fungal genomic DNA (gDNA) reads from endophyte-symbiotic plant parts $(n=4)$

\begin{tabular}{|c|c|c|c|c|}
\hline Plant part & Total no. reads $^{a}$ & Epichlö̈ coenophiala $\mathrm{e}^{\mathrm{b}}$ & $\%$ E. coenophiala gDNA ${ }^{\mathrm{c}}$ & cDNA/gDNA $^{d}$ \\
\hline Ovaries & $55,899,387$ & 19,863 & $0.035 \pm 0.003$ & $7.38 \pm 0.16$ \\
\hline Pseudostems & $30,972,606$ & 127,056 & $0.400 \pm 0.044$ & $2.35 \pm 0.44$ \\
\hline Lemma and palea & $34,642,438$ & 20,145 & $0.061 \pm 0.010$ & $16.86 \pm 0.39$ \\
\hline
\end{tabular}

a Total number of gDNA reads after filtering for quality and removing duplicate reads.

b Number mapped to the E. coenophiala e19 genome.

c Average percentage of E. coenophiala gDNA reads \pm standard error (SE).

${ }^{\mathrm{d}}$ Ratio of E. coenophiala read proportions, cDNA/gDNA $\pm \mathrm{SE}$. 
give the set of e4163 gene models called 'MAKER predicted transcripts' in the University of Kentucky Genome Projects database. By a combination of BLAST searches and phylogenetic analysis with predicted genes from most haploid Epichlö species, the likely ancestor contributing each homeolog was identified and, in this paper, homeologous genes are distinguished by the suffix ' $-b$ ' for those from LAE, ' $-f$ ' for those from $E$. festucae, or ' $-p$ ' for those from $E$. typhina subsp. poae. The E. coenophiala e4163 gene models were functionally annotated using BLASTx and InterproScan (Enright et al. 2002). High-quality RNA-seq reads were mapped to the E. coenophiala e4163 gene models with a threshold minimum of 10 reads per gene model, giving a total of 11,707 scored gene models. The reads were further normalized and analyzed by comparisons between plant parts (PS, IP, LP, and OV) in JMP Genomics (version 7.0; SAS Institute, Cary, NC, U.S.A.). A differentially expressed gene (DEG) was defined as exhibiting a significant $(P$ $\leq 0.01)$ and more than twofold difference in expression between different plant parts. Fungal gene expression profiles clustered according to plant parts (Fig. 1A). Also, expression in IP-1 and IP-s clustered with each other, so IP samples were considered together in further analysis. In principal component analysis (PCA), differences attributable to plant part accounted for $41 \%$ of the variation in fungal gene expression, the largest component

A

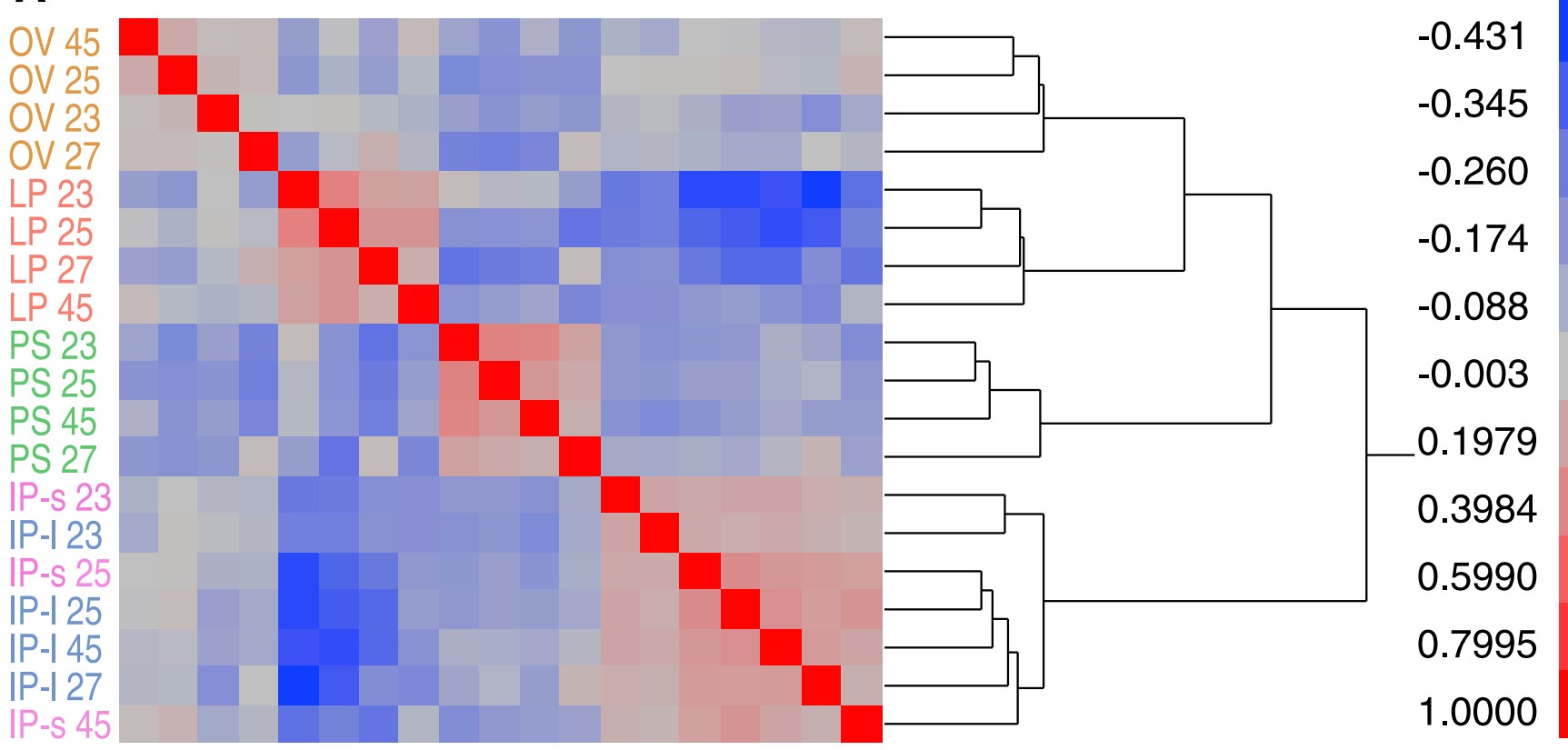

B

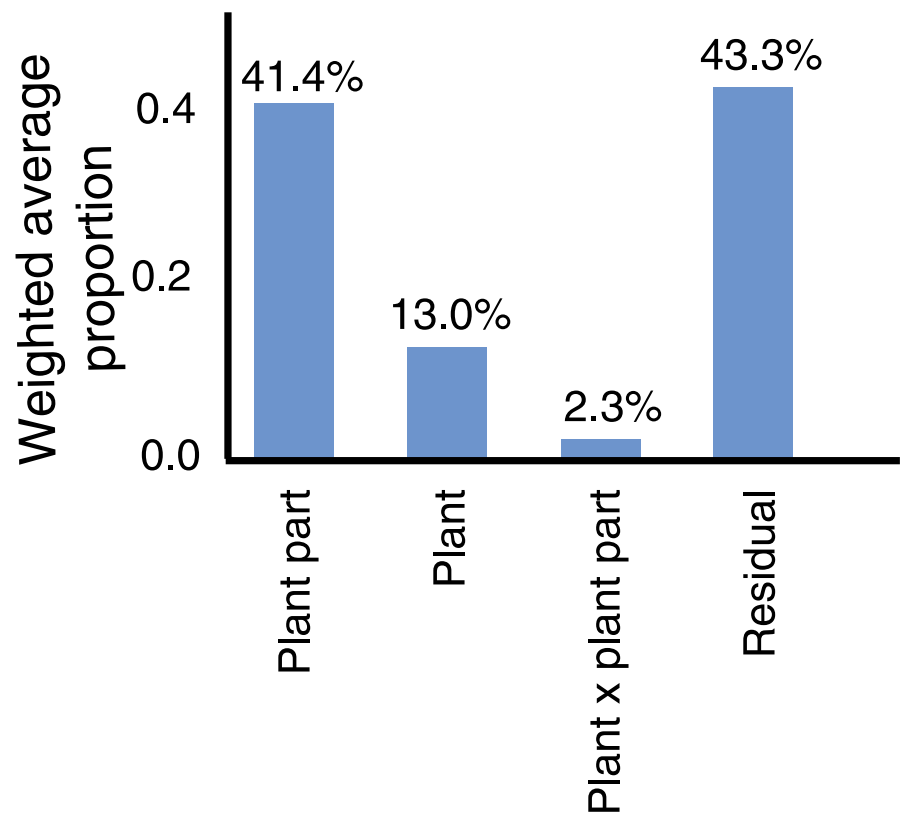

Fig. 1. Cluster and principal components analysis of endophyte gene expression in tall fescue plant parts. A, Hierarchical clustering on correlations (Ward method). B, Weighted average proportion across principal components associated with the proportion of the variance for each of the modeled fixed effects (and interactions). Model tested is: plant part, plant genotype, and interaction of plant part $\times$ plant genotype. Plant parts are: OV, ovary; IP-s, small inflorescence primordium; IP-1, large inflorescence primordium; LP, lemma and palea, and PS, pseudostems. Plant parts are numbered according to the designation of the source plant. 
other than the residual (Fig. 1B). Fungal DEGs are enumerated on Venn diagrams in Figure 2 and are graphed on volcano plots in Figure 3.

The endophyte DEGs between the four plant parts were analyzed using k-means clustering. After exploring several values of $\mathrm{k}$, we decided that 12 clusters gave good discrimination of expression patterns between plant parts (Fig. 4). The genes included in each cluster are listed in Supplementary Dataset S1. Cluster $P$ values were directly related to numbers of genes that they contained (Table 3 ).

The k-means clusters with OV $>$ PS included many stressrelated genes. Cluster 3 , with $\mathrm{OV} \approx \mathrm{LP} \approx \mathrm{IP}>\mathrm{PS}$ (197 genes), included genes tppA- $f$ and tppA-p, putatively encoding a trehalose-6-phosphate (T6P) phosphatase and tpsA- $b$, tpsA- $p$, tps $A-f$, and tps $B-f$, genes encoding trehalose-6-phosphate synthase, subunits of the trehalose synthesis complex (Svanström et al. 2014), and a homolog of bax-inhibitor-1 (BI-1, bxiA-f), which suppresses endoplasmic reticulum (ER) stress-induced apoptosis (Hückelhoven 2004). This cluster also included genes $c a t A-p$ for a catalase previously characterized as spore-specific (Cartwright and Scott 2013), catB- $p$ for another catalase, sodA- $b$ for $\mathrm{Cu} / \mathrm{Zn}$ superoxide dismutase (CuZnSOD), $c r d B-b$ for a copper-binding metallothionein (Viarengo et al. 2000), and genes for some protein chaperones including or related to heat-shock proteins (Hsps) (Verghese et al. 2012). Cluster 4, with OV $\approx$ IP > LP > PS (97 genes), included other putative genes for chaperones, a gene for catalase (catA-f), and a CLC chloride channel protein (voltage-gated anion channel; $c l c A-p$ ) (Oddon et al. 2007).

The k-mean clusters with PS $>$ OV were dominated by genes related to metabolism. Clusters 2 and 7, with genes more highly expressed in vegetative versus reproductive parts $(\mathrm{PS} \approx \mathrm{LP}>$ OV > IP), included most of the loline alkaloid pathway genes (lolC, lolF, lolD, lolU, lolO, lolE, lolN, lolM, and lolP) (Pan et al. 2014; Spiering et al. 2005); whereas cluster 10, with PS $>$ LP $\approx$ IP $>\mathrm{OV}$, included ergot alkaloid biosynthesis genes (eas $A-b$, $e a s C-b$, eas D- $b$, eas $G-b$, eas $F-b, c l o A-f$, and $c l o A-p$ ) (Florea et al. 2017), the gene for a putative small secreted protein related to syncollin ( $s s p A-p)$ (Antonin et al. 2002) and genes for major facilitator superfamily (MFS) proteins related to transporters for quinate, sugar, myoinositol, and proline (Geisse et al. 2002).

Cluster 9, with $\mathrm{PS} \approx \mathrm{LP} \approx \mathrm{OV}>\mathrm{IP}$, included a loline alkaloid (lolT) and ergot alkaloid (dmaW-f) gene, along with sodA-f, and some metabolism genes. Clusters 1 and 6 , with $\mathrm{LP}>\mathrm{IP} \approx \mathrm{OV} \approx$ PS, included $s s p A-f$ and genes for putative transporters belonging to ATP binding cassette (ABC) superfamilies. Cluster 8 , with IP $>\mathrm{LP} \approx \mathrm{OV} \approx \mathrm{PS}$, included genes for putative glycoside hydrolases, hydroxylases, monooxygenases, and genes for putative MFS transporters.

\section{Fungal genes are more highly expressed in OV than other plant parts.}

A total of 557 E. coenophiala DEGs with significantly different expression $(P \leq 0.01)$ in OV compared with each of the other plant parts are listed in Supplementary Dataset S2. Of the 427 DEGs between OV and PS, 276 were more highly expressed in $\mathrm{OV}(\mathrm{OV}>\mathrm{PS}$ ) (Figs. 2A and 3D) and 150 were more highly expressed in PS (PS $>$ OV). Table 4 shows results of gene ontology (GO) term enrichment analysis conducted on the OV $>$ PS and PS > OV DEGs, using lists of orthologs from the related fungus Metarhizium robertsii ARSEF 23.

Of the putative functions for OV > PS DEGs, the most prevalent were stress related, including 26 genes for protein folding (chaperones), seven genes for reactive oxygen species (ROS) scavenging activities, six for trehalose synthase complex subunits, and two for an apoptosis inhibitor (Supplementary Dataset S3). The other 235 OV > PS DEGs were for diverse functions, including 65 for various metabolic roles other than trehalose synthesis and 65 with unassignable roles.

A broad diversity of chaperones, including chaperonins and cochaperones, were encoded by OV > PS DEGs (Fig. 5A). These included Hsp30 (paralogous genes $h s p 30 A-p$ and $h s p 30 B-b)$, Hsp70 (hsp70B-b), Hsp80 (hsp80-p, hsp80-b, and $h s p 80-f$ ), Hsp88 ( $h s p 88-b$ ), and Hsp104 (hsp104-b, hsp104-f, and $h s p$ 104-p), mitochondrial chaperones DnaJ (dnaJ-b) and DnaK (dnaK-b, dnaK- $f$, and dnaK-p), type I chaperonins Cpn 10 (cpn10-b and cpn10-p) and Cpn60 (cpn60-b and cpn60-p), type II chaperonin-containing complex epsilon subunit $(c c t E-b)$ (Kubota et al. 1995), cochaperones AHA-1 (ahaA-p) (Meyer et al. 2004), Sbal (sbaA-p) (Fang et al. 1998), and Sti1 (stiA-p and stiA-f) (Lotz et al. 2008), and Hsp70 nucleotide exchange factor $(f e s A-b)$. Other significant OV > PS DEGs (Fig. 5B) putatively encoded three trehalose synthesis complex subunits

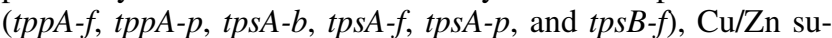
peroxide dismutase (CuZnSOD; $\operatorname{sod} A-b$ and $\operatorname{sod} A-f)$, the 'sporespecific' catalase (catA-f and catA-p), a CLC chloride channel protein $(c l c A-p)$, a copper-binding metallothionein $(c r d B-b)$, the BI-1 homolog (bxiA-f and bxiA-p), and a homolog of yeast (Saccharomyces cerevisiae) autophagy 18 protein (atg18-b) (Hückelhoven 2004).

Comparing OV and IP, 84 DEGs were significantly more highly expressed in OV (OV > IP) (Figs. 2A and 3A). These included genes for loline alkaloid biosynthesis enzymes, trehalose synthesis complex subunits, a homolog of yeast DNA damageresponsive protein DDR48, a putative glycosyl transferase, and putative glucose repressible protein Grg1 $(\operatorname{grg} A-b)$ (Ambrose and Belanger 2012), as well as sodA-f, sodA-b, crdB-b, catA-p, and the Nc25 cyclic peptide gene gigA- $f$ (Johnson et al. 2015).

Of 440 fungal DEGs between OV and LP, 343 were OV $\geq$ LP. These included a gene putatively encoding a copper chaperone for CuZnSOD (ccsA-p) (Culotta et al. 1997) as well as dnaJ-p,
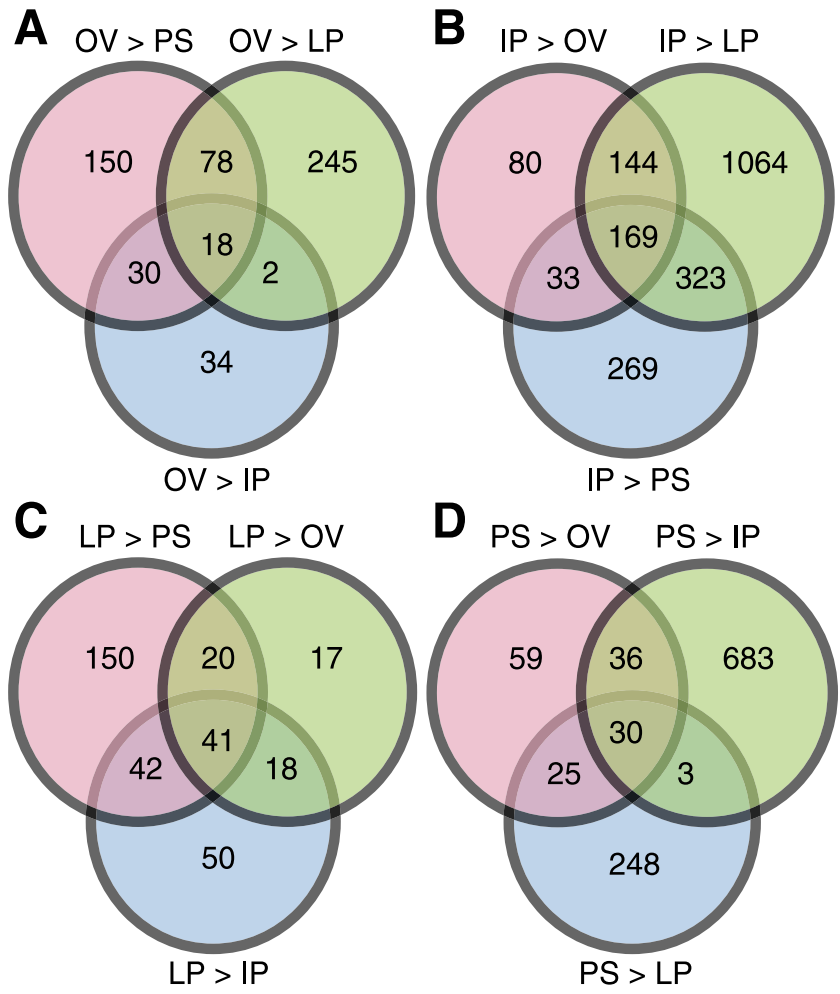

Fig. 2. Venn diagram comparing endophyte differentially expressed genes (DEGs) in tall fescue across plant parts. Highly expressed DEGs in A, ovaries (OV), B, inflorescence primordium (IP), C, lemma and palea (LP), and $\mathbf{D}$, pseudostems (PS), compared with other plant parts. 
A

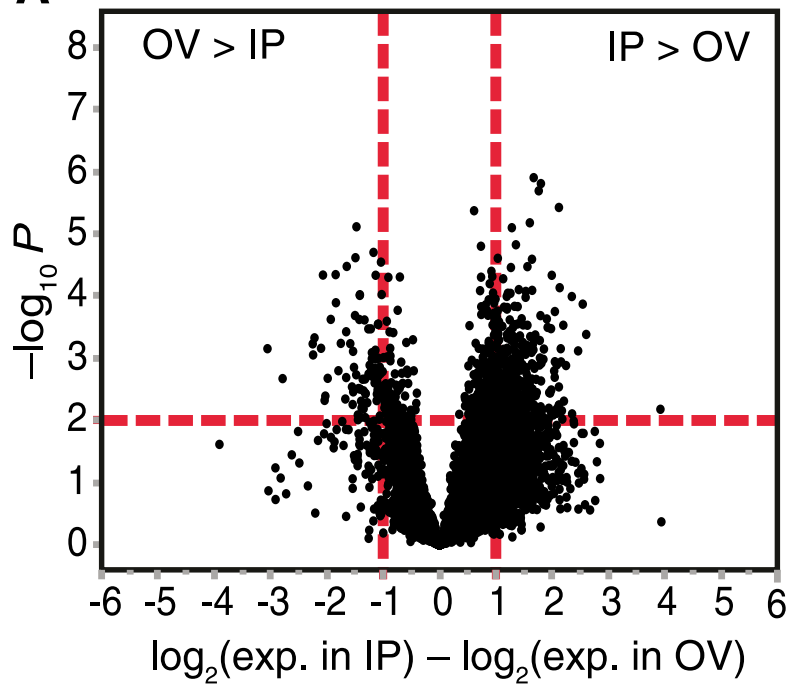

B

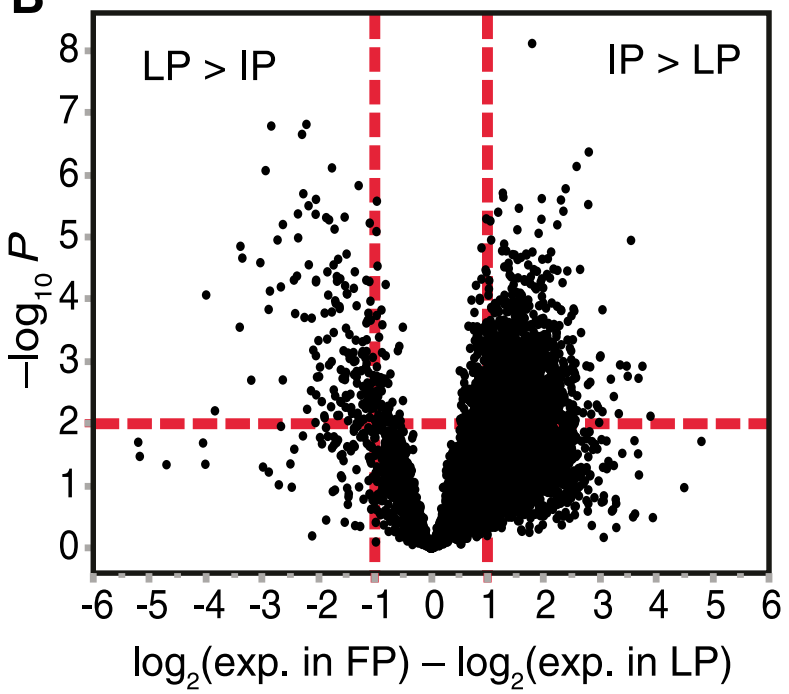

C

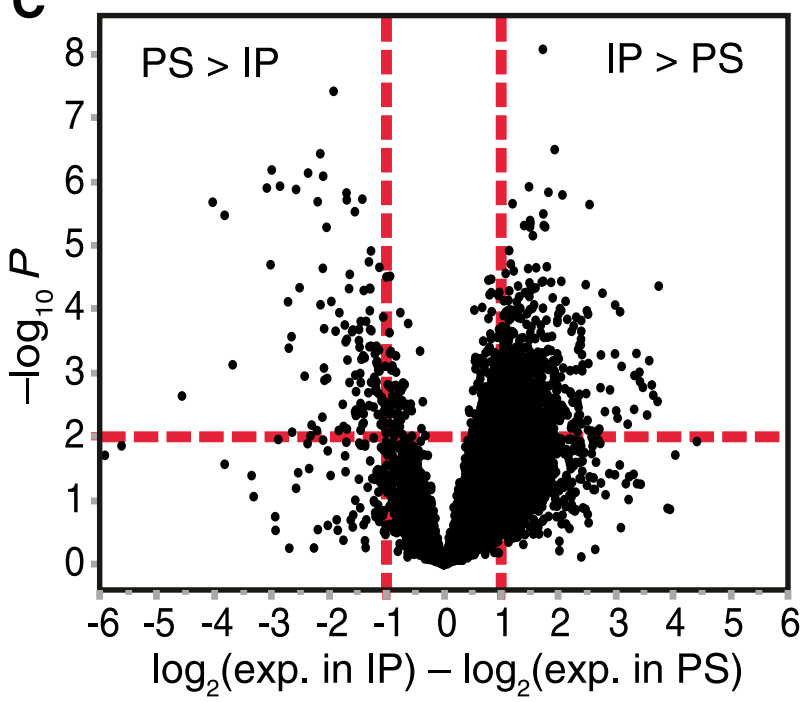

D

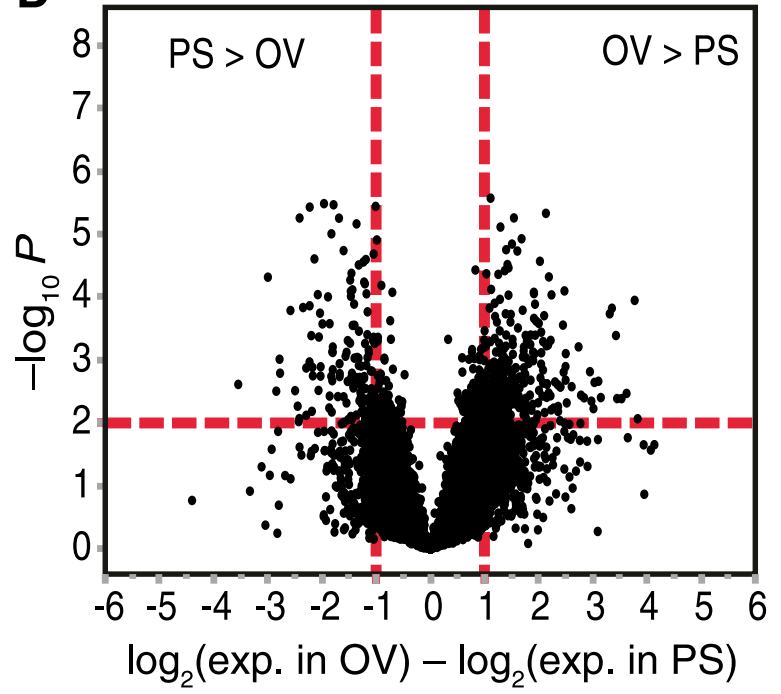

E

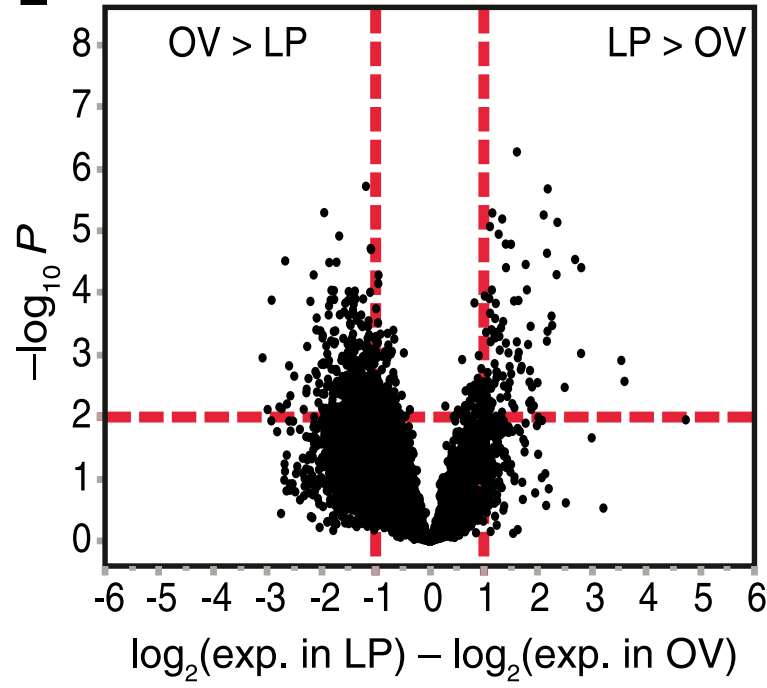

F

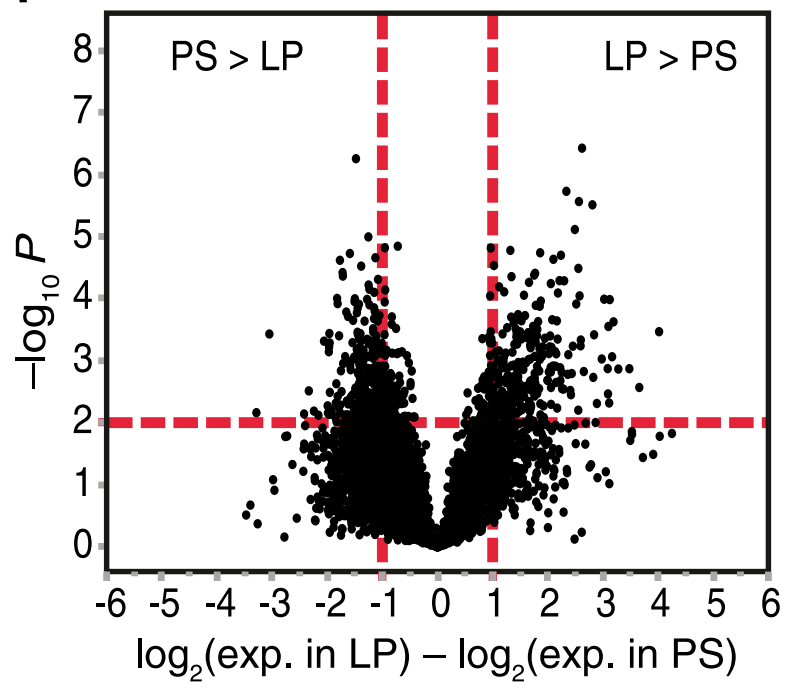

Fig. 3. Volcano plots comparing endophyte gene expression in different tall fescue plant parts. Endophyte gene expression in A, inflorescence primordium (IP) versus ovaries (OV), B, IP versus lemma and palea (LP), C, IP versus pseudostems (PS), D, OV versus PS, E, LP versus OV, and F, LP versus PS. Vertical dashed lines indicate the twofold cut-off for expression differences, and horizontal dashed lines indicate the minimum $P$ value for significance $=0.01$. 
sodA- $f, \operatorname{sod} A-p$, catA-f, tppA- $f$, tppA- $p$, atg $18-b$, and $\alpha$-tubulin genes $t b a A-p$, tbaA-f, and tbaB-p (Figs. $2 \mathrm{~A}$ and $3 \mathrm{E}$ ).

\section{Fungal genes more highly expressed}

in IP than other plant parts.

The 2,082 E. coenophiala DEGs more highly expressed in IP compared with other plant parts are listed in Supplementary Dataset S4. The 794 IP > PS DEGs (Figs. 2B and 3C) included putative chaperone genes $h s p 88-f, h s p 88-b, h s p 70 B-f, h s p 70 B-b$, $h s p 70 A-b, h s p 30 B-b, d n a J-b, d n a J-p, c p n 60-b, c p n 60-p, c p n 10-b$, cpn10-p, stiA-p, and all three homeologs, each, of hsp104, hsp 80 , $h s p 78$, dnaK, and fesA. Also, IP > PS were $c a t A-f$, sodA-f, and $c l c A-p$, genes putatively encoding glycoside hydrolase family proteins and transporters, $\alpha$-tubulin genes $t b a B-p$ and $t b a B-f$, and $\beta$-tubulin genes tubB- $f$ and $t u b B-b$. The 1,700 fungal IP $\geq$ LP DEGs (Figs. 2B and 3B) included cpn10-p, dnaJ-p, hsp 70A-b, and putative genes for ER-localized chaperone $\operatorname{BiP}($ bipA- $p$ ) and heat-shock factor binding protein $1(h f b A-b)$. This set also included $\operatorname{sod} A-f$, cat $A-p$, and genes putatively encoding glycoside hydrolases, salicylate monooxygenases, protein kinases, chitinase, trehalase, a gibberellin 20-oxidase homolog, transporters for glucose, peptides, quinate, folate and phosphate, $\alpha$-tubulin

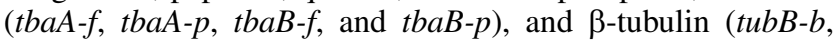
tubB-f, and tubP-f).

Comparing the different stages of reproductive development revealed $426 \mathrm{IP}>$ OV DEGs (Figs. 2B and 3A), including genes putatively encoding transporter proteins, salicylate monooxygenases, glycosyl hydrolases, protein kinases, $\alpha$-tubulin ( $t b a B-p)$, and $\beta$-tubulin $(t u b B-f)$. The remaining 169 DEGs, which were more highly expressed in IP than in all the other three plant parts (Fig. 2B), included genes putatively encoding glycoside hydrolases, calcium/calmodulin-dependent protein kinase $\mathrm{C}$, and transporters.

\section{Fungal genes more highly expressed} in LPs than plant parts.

The 338 E. coenophiala DEGs more highly expressed in LP compared with other plant parts are listed in Supplementary

Table 3. Cluster analysis of Epichloë coenophiala differentially expressed genes $(P \leq 0.01)$ in different host plant parts

\begin{tabular}{lcc}
\hline Cluster & No. of genes & Cluster $\boldsymbol{P}$ value \\
\hline 1 & 30 & 0.011 \\
2 & 14 & 0.005 \\
3 & 197 & 0.071 \\
4 & 97 & 0.035 \\
5 & 293 & 0.106 \\
6 & 76 & 0.027 \\
7 & 9 & 0.003 \\
8 & 122 & 0.044 \\
9 & 130 & 0.047 \\
10 & 76 & 0.027 \\
11 & 1,031 & 0.371 \\
12 & 700 & 0.252 \\
Total & 2,775 & 1.000 \\
\hline
\end{tabular}
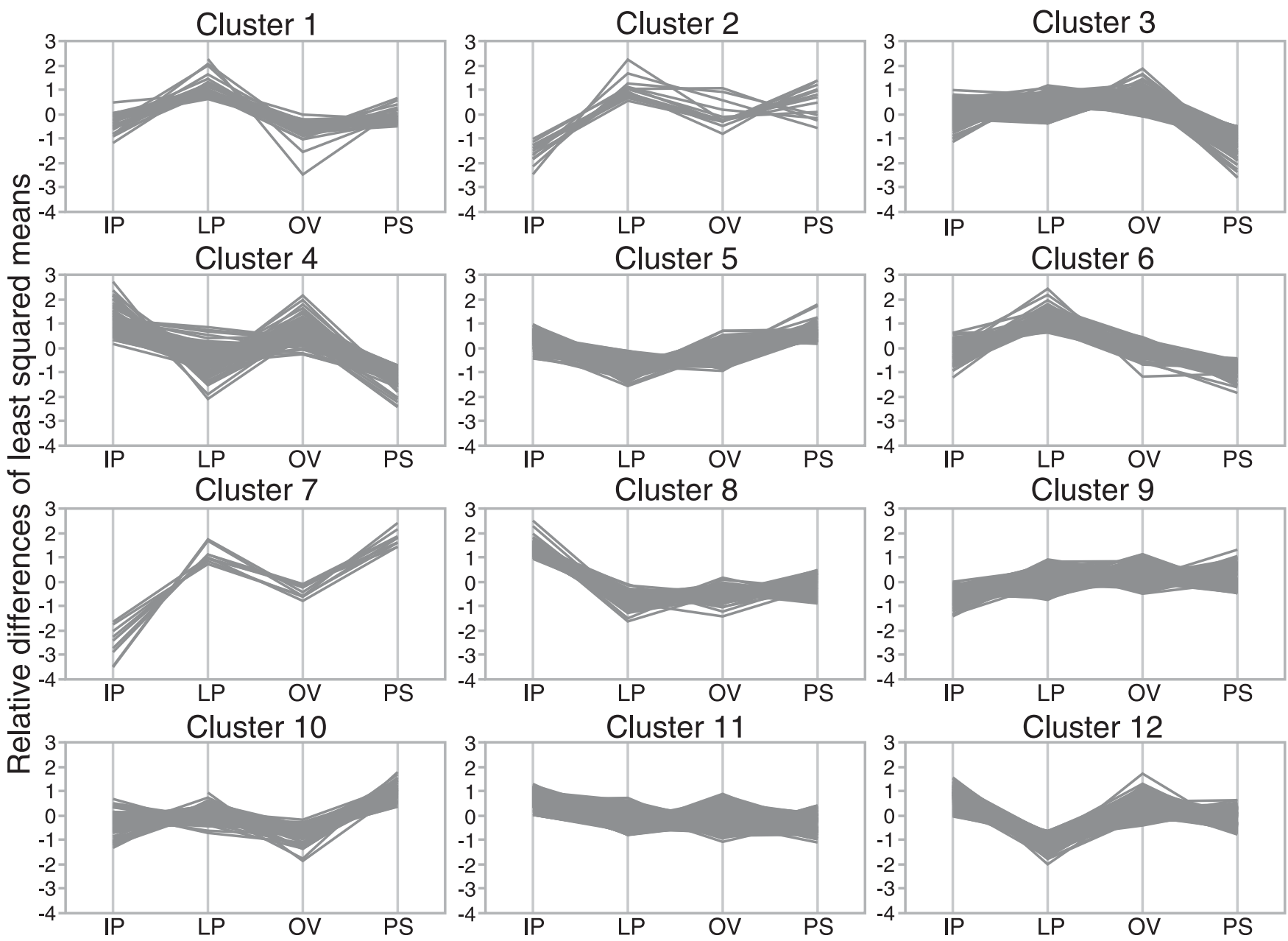

Fig. 4. Cluster analysis of fungal differentially expressed genes across the plant parts (pseudostems [PS], lemma and palea [LP], ovaries [OV], inflorescence primordium [IP]) using k-means. 
Dataset S5. Of these, 253 DEGs were LP > PS (Figs. 2C and 3F), many of which were also identified as OV $>$ PS and IP $>$ PS. These included 18 homeologs for chaperones as well as catA-p, $\operatorname{grg} A-b$, $c r d B-b, \operatorname{ssp} A-f$, and one homeolog for trehalose synthesis complex subunit TpsA (tpsA-f). Also in this group were genes for putative transporters belonging to ABC and MFS families. The $151 \mathrm{LP}>\mathrm{IP}$ DEGs (Figs. 2C and 3B) included $c a t B-p$, gig $A-f$, gig $A-b$, grg $A-b$, most loline alkaloid pathway genes, and putative genes for $\mathrm{ABC}$ transporters and a myoinositol transporter-related protein. The 96 LP > OV DEGs (Fig. 2C and 3E) included many that were also $\mathrm{PS}>\mathrm{OV}$, such as gigA- $b$, sspA-p, loline alkaloid pathway genes, and putative genes for transporters belonging to MFS and $\mathrm{ABC}$ superfamilies.

\section{Fungal genes more highly expressed in PS than other plant parts.}

The 1,084 E. coenophiala DEGs expressed at significantly higher levels in PS compared with other plant parts are listed in Supplementary Dataset S6. The 150 PS > OV DEGs (Figs. 2D and 3D) included loline and ergot alkaloid pathway genes, some genes for putative sugar and amino acid transporters, sspA$p$, gigA- $b$, and $g i g A-f$ (Fig. 6). The 752 PS > IP DEGs (Figs. 2D and $3 \mathrm{C}$ ) also included the loline alkaloid and most ergot alkaloid genes, gigA- $b$, gigA- $f$, and $\alpha$-tubulin $(t b a A-f)$ and $\beta$-tubulin $(t u b P-f)$ genes. Comparing fungal expression in vegetative plant parts, the 306 PS > LP DEGs (Figs. 2D and 3F) included genes for putative $\mathrm{ABC}$ and MFS transporters for quinate, phosphate, sugars, and amino acids, $\operatorname{ccs} A-p$, and most ergot alkaloid genes.

GO term enrichment analysis against the 94 unique $M$. robertsii orthologs of PS > OV DEGs indicated significant enrichment of genes associated with membranes and transporters (Table 4). Biosynthetic genes were not identified in this analysis, but this may be because genes for secondary metabolite biosynthesis were less likely to have orthologs in $M$. robertsii. For example, orthologs of most ergot alkaloid genes, but none of the loline biosynthesis genes, are identifiable in the $M$. robertsii ARSEF 23 genome sequence.

\section{Fungal gene expression in the Brachypodium sylvaticum-Epichlö̈ sylvatica symbiotic system.}

We also compared E. sylvatica gene expression profiles in B. sylvaticum OV and PS. As a haploid, E. sylvatica possessed only a single copy rather than multiple homeologs of each gene. Lacking sufficient material for a replicated study and analysis of significance, we instead list those endophyte genes with at least fivefold apparent difference in expression between the two plant parts. The 422 genes identified as fivefold or greater $\mathrm{OV}>$ PS (Supplementary Dataset S7) included putative chaperonin and chaperone genes cpn 10 , dnaJ, hsp30A, hsp30B, hsp 70A, hsp 78 and $h s p 104$, bxiA, atg 18, catA, tppA, and putative genes for eight transcription factors, including one related to heatshock factors. The 671 genes that apparently were expressed at fivefold or greater PS > OV included sspA, the siderophore biosynthesis gene sidN (Koulman et al. 2012), the small GTPase gene racA (Tanaka et al. 2008), the NoxA regulator gene, noxR (Takemoto et al. 2006), and putative transporter protein genes (Supplementary Dataset S8).

\section{Endophyte effects on expression of tall fescue genes in OV.}

Gene-expression profiles in tall fescue OV were compared between symbiotic $(\mathrm{E}+)$ and asymbiotic $(\mathrm{E}-)$ clones of each of the four clone pairs. A total of 137 and 65 million reads were obtained from E+ OV and E- OV, respectively. After filtering out fungal reads, the remaining reads were mapped to the previously described tall fescue transcriptome assembly designated TF153K (Dinkins et al. 2017). Of the filtered reads, averages of $83 \%$ from E+ clones and $81 \%$ from E-clones mapped to the TF153K assembly (Table 5). Variance decomposition using PCA indicated that $7.2 \%$ of the variation in plant gene expression was due to endophyte status (E+ versus E-), $84.2 \%$ was due to plant genotype, $1.8 \%$ was due to endophyte $\times$ genotype interaction, and $6.9 \%$ was residual. Only eight plant DEGs were identified with significantly different expression between E+ and E- plants $(P<0.001$, fold change $\geq 2)$, and all were more highly expressed in E+ than E- OV (Fig. 7). For three of these, no molecular function or biological process GO terms were identified, for another three, the GO terms were related to protein synthesis or processing, and for the remaining two, the GO terms were for metabolic process and potassium ion transport (Supplementary Dataset S9).

\section{Plant gene expression analysis \\ in Brachypodium sylvaticum $\mathrm{E}+$ and $\mathrm{E}-\mathrm{OV}$.}

Plant gene expression profiles of $\mathrm{E}+$ and $\mathrm{E}-$ B. sylvaticum OV were compared to determine changes in the plant due to the endophyte presence. Again, because of insufficient numbers of B. sylvaticum plants for statistical analysis, we did not determine significance, but we identified those genes with more than fourfold differences in apparent expression between E+ and E- OV (Supplementary Dataset S10). Out of 32,255 gene hits to the Brachypodium distachyon genome assembly, only 116 genes were identified as differentially expressed between $\mathrm{OV}$ of $\mathrm{E}+$ and $\mathrm{E}-$ plants. Of those, 61 were more highly expressed in $\mathrm{E}$ - than $\mathrm{E}+\mathrm{OV}$, of which 49 were associated with five biological function GO terms, namely, cellular processes

Table 4. Results of gene ontology (GO) term enrichment analysis of differentially expressed genes

\begin{tabular}{|c|c|c|c|c|c|}
\hline GO ID/namespace ${ }^{a}$ & GO name & Exact $P$ value & Adjusted $P$ value & No. of genes/category & No. of genes/input \\
\hline \multicolumn{6}{|c|}{ Expression in ovaries $>$ expression in pseudostems } \\
\hline GO:0006950/BP & Response to stress & $1.92 \mathrm{E}-11$ & 4.31 E-9 & $11 / 35$ & $11 / 172$ \\
\hline GO:0006457/BP & Protein folding & $5.89 \mathrm{E}-8$ & $6.62 \mathrm{E}-06$ & $9 / 42$ & $9 / 172$ \\
\hline GO:0005992/BP & Trehalose biosynthetic process & $2.58 \mathrm{E}-05$ & 0.001936 & $3 / 4$ & $3 / 172$ \\
\hline GO:0051082/MF & Unfolded protein binding & 0.000807 & 0.043673 & $4 / 23$ & $4 / 172$ \\
\hline GO:0009408/BP & Response to heat & 0.001045 & 0.043673 & $2 / 3$ & $2 / 172$ \\
\hline GO:0005524/MF & ATP binding & 0.001165 & 0.043673 & $23 / 623$ & $23 / 172$ \\
\hline \multicolumn{6}{|c|}{ Expression in pseudostems $>$ expression in ovaries } \\
\hline GO:0022891/MF & $\begin{array}{l}\text { Substrate-specific transmembrane } \\
\text { transporter activity }\end{array}$ & $1.16 \mathrm{E}-05$ & 0.000902 & $6 / 40$ & $6 / 94$ \\
\hline GO:0022857/MF & Transmembrane transporter activity & $1.3 \mathrm{E}-05$ & 0.000902 & $7 / 61$ & $7 / 94$ \\
\hline GO:0055085/BP & Transmembrane transport & $2.01 \mathrm{E}-05$ & 0.000929 & $18 / 458$ & $18 / 94$ \\
\hline GO:0016021/CC & Integral component of membrane & $5.92 \mathrm{E}-05$ & 0.002058 & $23 / 746$ & $23 / 94$ \\
\hline GO:0006044/BP & $\mathrm{N}$-acetylglucosamine metabolic process & 0.000171 & 0.004753 & $2 / 2$ & $2 / 94$ \\
\hline GO:0005215/MF & Transporter activity & 0.000421 & 0.009762 & $6 / 75$ & $6 / 94$ \\
\hline GO:0008643/BP & Carbohydrate transport & 0.000515 & 0.010219 & $4 / 29$ & $4 / 94$ \\
\hline
\end{tabular}

${ }^{\mathrm{a}} \mathrm{BP}=$ biological process, $\mathrm{CC}=$ cellular component, $\mathrm{MF}=$ metabolic function. 
(22 genes), lyase activity (five genes), heterocyclic metabolic process (five genes), nitrogen compound metabolic process (12 genes), and cellular nitrogen compound metabolic processes (five genes). Of the 55 genes that were fourfold or greater more highly expressed in E+ OV, none had associated GO terms.

\section{Tall fescue gene expression.}

We also compared plant gene expression profiles in PS, OV, IP, and LP parts of E+ tall fescue plants. As expected, many plant genes were differentially expressed between the different plant parts (data not shown). A heat map based on plant gene expression profiles (Supplementary Fig. S2) grouped the vegetative (PS and LP) parts and reproductive (IP and OV) parts in separate clusters. Many of the genes related to photosynthesis were expressed at similar levels in the PS and LP, whereas IP and OV had similar expression levels to many genes related to flowering and reproduction.

The plant genes that were differentially expressed between PS and OV were subjected to pathway analysis by AgriGO, with the $B$. distachyon gene models to identify GO pathways that were over- or underrepresented among the DEGs. Plant genes that were expressed more highly in OV compared with PS were in 53 GO categories mainly associated with biosynthetic process, metabolic processes or regulation of transcription (Supplementary Fig. S3), whereas plant genes that were more highly expressed in PS over OV had 129 significant GO terms. Some of the overrepresented GO pathways based on biological processes were classified as metabolic processes, protein amino acid phosphorylation, and apoptosis. Also included were response to stimulus, including response to oxidative stress, photosynthesis and light harvesting, and pollen pistil interaction and recognition of pollen (Supplementary Fig. S4).

\section{DISCUSSION}

Vertical transmission through host seeds is the main or only mode of transmission for asexual Epichloë species, thus essential to maintain their symbiosis through successive host
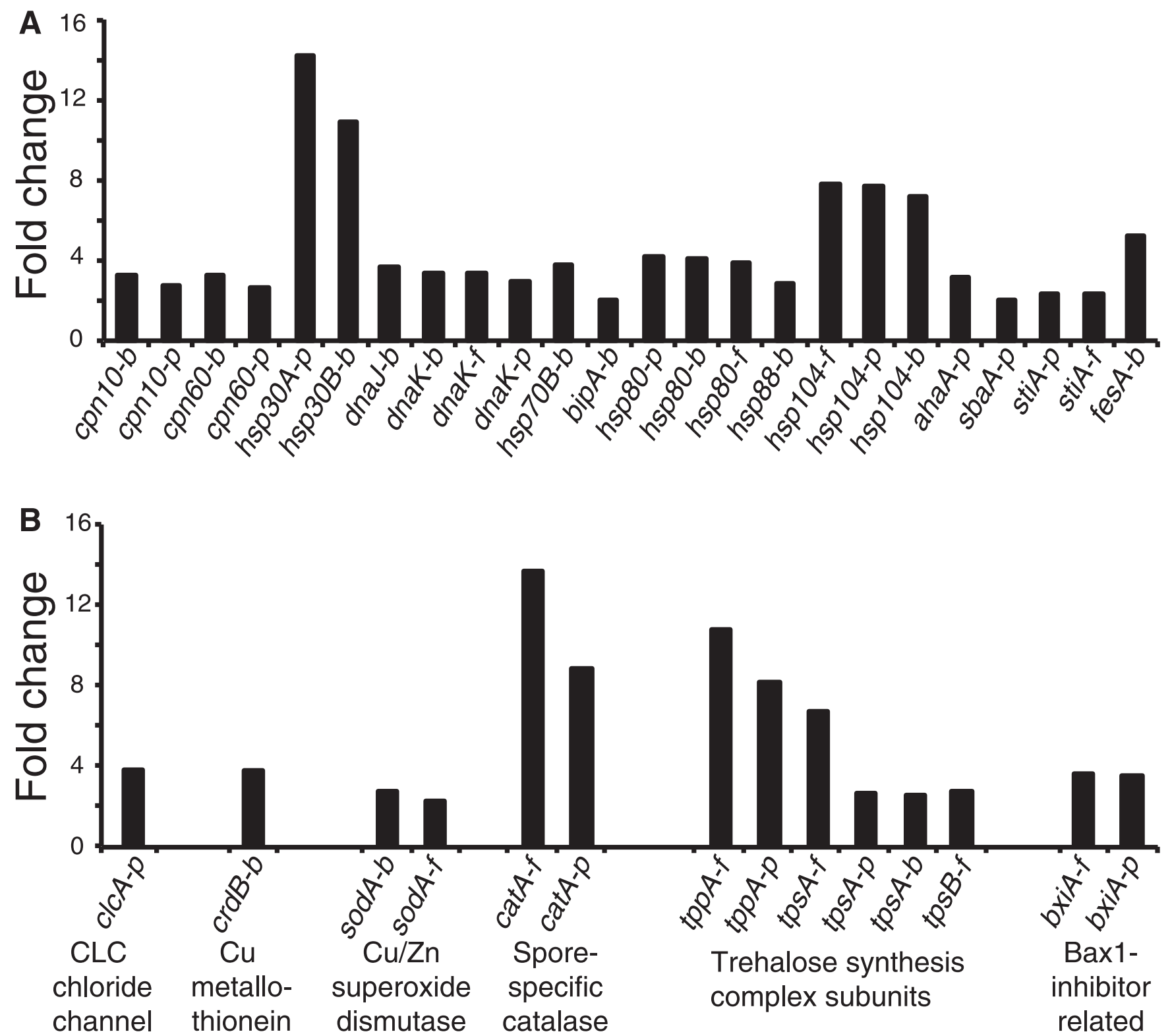

Fig. 5. Endophyte differentially expressed genes (DEGs) more highly expressed in ovaries (OV) compared with pseudostems (PS) $(P \leq 0.01$, fold difference $\geq$ 2). A, Genes for protein chaperones, chaperonins, and cochaperones. B, DEGs related to reactive oxygen species scavenging, trehalose biosynthesis, and apoptosis inhibition. The $y$ axis represents the fold change and the $x$ axis represents gene or protein names. 
generations. We conducted transcriptome profiling of the plant and fungus in the tall fescue-E. coenophiala symbiotic system to identify pathways that are apparently regulated over the host life cycle, including early stages of this important vertical transmission process. Our results suggest that E. coenophiala undergoes a shift from metabolic processes, such as alkaloid production in vegetative host parts, to scavenging ROS, T6P and trehalose biosynthesis, and expression of protein chaperones (including chaperonins and cochaperones) in host reproductive parts. Major pathways that undergo change are particularly evident when comparing endophyte transcriptomes in preanthesis $\mathrm{OV}$ and vegetative PS. Alkaloid biosynthesis genes and many putative transporter genes are significantly more highly expressed in PS as well as in the floral bracts (LP) compared with OV and IP. In contrast, genes associated with stress responses, protein folding, and trehalose synthesis are more highly expressed in OV and IP than in PS and LP. For example, we found that genes putatively encoding chaperone proteins Hsp30 and Hsp104, catalase CatA, and trehalose synthesis complex subunits are expressed at more than fivefold higher levels in OV over PS, and almost all other genes for chaperones, a copper-binding metallothionein, a CLC chloride channel, and the homolog of apoptosissuppressive BI-1 are expressed at significantly and at twofold or more higher levels in OV over PS. Furthermore, the observation that many of these genes are significantly more highly expressed in IP and LP than PS suggests that the transcriptomic shift in E. coenophiala begins early in inflorescence development and continues in both reproductive (OV) and vegetative (LP) parts of the young florets.

We also compared gene expression by E. sylvatica in B. sylvaticum OV and PS, and we observed similar differences to those in the tall fescue-E. coenophiala system. In particular, $c a t A, \operatorname{tpp} A$, bxiA, and genes for chaperones were expressed at more than fourfold higher levels in OV compared with PS. This result provides confirmatory support for the hypothesis that such shifts in fungal gene expression may be important for establishing or regulating fungal growth in host reproductive tissues and might be common across grass-Epichloë systems.
Of 276 E. coenophiala DEGs with more than twofold higher expression in OV than PS, 211 have assignable or putative functions, and, of these, $52(25 \%)$ had significantly enriched GO terms, mostly associated with stress responses and including protein chaperones (Verghese et al. 2012), trehalose synthesis, and ROS scavenging enzymes. The possible explanation that the sampled OV may actually be stressed is unsupported by the plant gene expression profiles, which give no indication of a stress response. There is also no indication that the endophyte causes a stress response in its host, either when comparing tall fescue gene expression in E+ versus E- OV in this study or E+ versus E- PS in our previous study (Dinkins et al. 2017). Furthermore, an extensive ultrastructural study of the perennial ryegrass (L. perenne)E. festucae and tall fescue-E. coenophiala systems has shown no indication that hyphae in OV are stressed (Philipson and Christey 1986), which contrasts with observations of some mutant Epichloë strains that manifest aberrant and highly vacuolated hyphae in symbio (Johnson et al. 2013; Tanaka et al. 2008, 2012). Therefore, we suggest that stress-related genes that are highly expressed by the endophyte in OV and IP may have functions, other than stress responses, to facilitate vertical transmission and maintain health of the endophyte and host during this process.

In interpreting the transcriptome differences and formulating hypotheses regarding their functional significance, it is important to consider the nature of the plant parts sampled, which consist of different mixtures of tissue types. The relative abundances of meristematic, elongating, and mature tissues undoubtedly differ greatly between the sampled plant parts, so we consider the possibility that some-perhaps most-of the observed transcriptome differences in the endophyte reflect its different growth patterns and metabolism in different host tissue types. We expect that IP and OV should have relatively high proportions of meristem and differentiating plant cells compared with LP and PS, which, instead, should have higher proportions of elongating cells and, perhaps, mature plant cells. Schmid et al. (2017) observed that, in perennial ryegrass, E. festucae var. lolii expresses genes for the indole-diterpene and ergot alkaloids more highly in plant parts with more mature tissues, which is

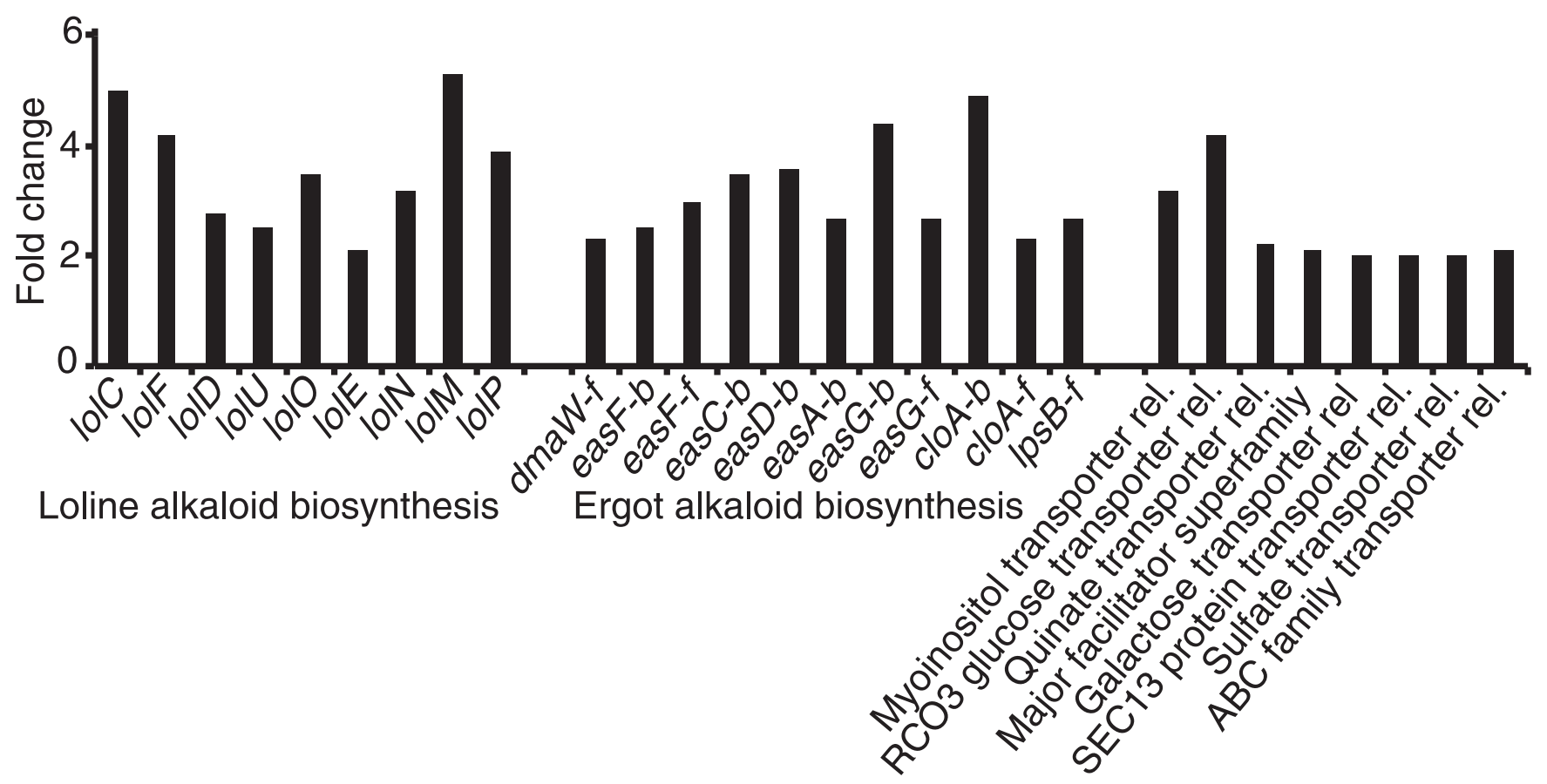

Fig. 6. Endophyte differentially expressed genes more highly expressed in pseudostems compared with ovaries. The $y$ axis represents the fold change and the $x$ axis represents gene or protein names. 
consistent with our observed differences in E. coenophiala loline and ergot alkaloid gene expression. The associations of alkaloid gene expression with mature tissues contrasts with the relatively high expression of chaperone genes in plant parts that are rich in differentiating meristem tissues. We propose that the underlying reason for high chaperone gene expression may be that young plant tissues undergo rapid colonization by the endophyte.

Relevant to our proposed explanation are the observations that Hsp genes are among the most highly expressed in germinating pollen and growing pollen tubes compared with mature pollen in Arabidopsis thaliana (Wang et al. 2008). Also, Magnard et al. (1996) report expression of Hsp18, Hsp60 (=Cpn60) and Hsp70 proteins during microsporogenesis in Zea mays. Authors of both plant studies suggest that the need for protein chaperones is high, due to high levels of protein production during rapid growth of developing or germinating pollen. The same may be true of E. coenophiala, such that relatively high Hsp gene expression may reflect an increased need for chaperones during colonization of differentiating plant tissues. This possibility is further supported by the more abundantly branched hyphal network in leaf primordia compared with elongation zones and mature zones of the plant leaves (Christensen et al. 2008).

Would rapid growth and colonization of host meristematic regions fit with expression patterns for other pathways in addition to protein chaperones? The strong evidence for an autoregulatory role of ROS suggests that it does. Mutations disrupting the NoxA NADPH oxidase complex of E. festucae reduce ROS production and also lead to increased growth and branching in plant cell-elongation zones, and host plants with such mutants are stressed and stunted (Tanaka et al. 2012). Therefore, autoregulatory inhibition of endophyte growth in host elongation zones and mature tissues is important for healthy symbiosis, whereas such growth inhibition probably must be released to allow the fungus to colonize differentiating plant tissues by invasive tip growth and branching. We suggest that the endophyte may upregulate genes involved in ROS scavenging as a mechanism to remove this inhibitory signal. Such genes would include those for CuZnSOD and catalase, as well as those for CLC chloride channel and copper metallothionein, which ensure availability of copper ions for the CuZnSOD (discussed below). Perhaps the same result could be achieved by downregulating expression of the gene for NoxA or other interactors (Tanaka et al. 2012), but we did not see any significant change in those genes in the tall fescue-E. coenophiala system. Although the number of noxA reads did not meet the threshold for analysis, we detected no significant changes in E. coenophiala genes for NoxA regulatory proteins in OV versus PS (Supplementary Dataset S11). However, in B. sylvaticum OV the E. sylvatica racA and noxR genes were expressed, respectively, at only 20 and $10 \%$ of their mRNA levels in PS. Possibly, transcriptional control of ROS signaling in E. coenophiala, in contrast to E. sylvatica, may be restricted to genes for ROS scavenging and tolerance activities. Conceivably, BI-1 and the trehalose synthesis complex are also involved in releasing this autoregulation, considering relationships between ROS, trehalose, and apoptosis in eukaryotic systems (Fath et al. 2001; Lu et al. 2011).

Table 5. Fungal and plant RNA-seq reads from endophyte-symbiotic (E+) and endophyte-free (E-) ovaries (OV)

\begin{tabular}{|c|c|c|c|c|c|}
\hline Sample & $n$ & $\begin{array}{l}\text { Total high- } \\
\text { quality } \\
\text { Illumina } \\
\text { reads }\end{array}$ & $\begin{array}{c}\text { Mapped to } \\
\text { Epichlö̈ } \\
\text { coenophiala } \\
\text { e4163 }\end{array}$ & $\begin{array}{c}\text { Proportion } E \text {. } \\
\text { coenophiala } \\
\text { e4163 genes }\end{array}$ & $\begin{array}{l}\text { Mapped to } \\
\text { TF153K }\end{array}$ \\
\hline $\mathrm{E}+\mathrm{OV}$ & 4 & $180,054,665$ & 246,909 & 0.137 & $149,597,656$ \\
\hline $\mathrm{E}-\mathrm{OV}$ & 3 & $65,487,048$ & 6,691 & 0.010 & $53,306,982$ \\
\hline
\end{tabular}

CuZnSOD converts superoxide anion $\left(\mathrm{O}_{2}^{-}\right)$to $\mathrm{H}_{2} \mathrm{O}_{2}$, and catalases then decompose $2 \mathrm{H}_{2} \mathrm{O}_{2}$ to $2 \mathrm{H}_{2} \mathrm{O}+\mathrm{O}_{2}$. Increased levels of fungal $\mathrm{CuZnSOD}$ have been reported to be expressed by $E$. festucae var. lolii in symbiosis with perennial ryegrass compared with cultures, suggesting a possible role of $\mathrm{CuZn}$ SOD in symbiosis (Zhang et al. 2011). The CLC chloride channel and copper metallothionein, for which putative genes ( $c l c A$ and $c r d B$, respectively) were also highly expressed in $\mathrm{OV}$, are involved in copper homeostasis and are important for CuZnSOD activity (Cohu and Pilon 2007; Harris 1992). The CLC chloride channel is a regulator of intracellular copper trafficking (Oddon et al. 2007) and copper metallothionein helps scavenge free copper ions (Viarengo et al. 2000). In Asperigillus nidulans, mutants of the CLC chloride channel gene show reduced activity of CuZnSOD due to impaired copper balance in the cell (Oddon et al. 2007), indicating that regulation of copper availability is important for this ROS-scavenging function.

The relatively high expression of E. coenophiala genes for biosynthesis of T6P and trehalose in OV and IP suggests roles for these versatile disaccharides in endophyte colonization of reproductive plant organs. It is noteworthy that these molecules also have roles in other symbioses, such as legume root nodules and mycorrhizae (Lunn et al. 2014; Suárez et al. 2008). Trehalose and T6P have a wide range of functions in plants, fungi, and other organisms. Numerous reports indicate that trehalose can protect cells from various stresses (Iordachescu and Imai 2008; Karim et al. 2007; Redillas et al. 2012). Trehalose helps to stabilize macromolecules during freezing and desiccation by substituting for water (Leslie et al. 1995). Also, trehalose appears to protect against ROS. For example, yeast trehalose biosynthesis mutants subjected to heat shock are more sensitive to oxidative damage and $\mathrm{H}_{2} \mathrm{O}_{2}$ than are unshocked cells (Benaroudj et al. 2001). Given its protective effects, enhanced expression of T6P- and trehalose-biosynthesis genes by the endophyte is in keeping with enhanced expression of its other stress-related genes in reproductive versus vegetative plant parts. Furthermore, in plant-pathogenic fungi, trehalose levels can mediate turgor for penetration of plant tissues (Foster et al. 2003). Conceivably, trehalose may similarly regulate turgor of E. coenophiala hyphae and thereby facilitate colonization of young or reproductive plant tissues.

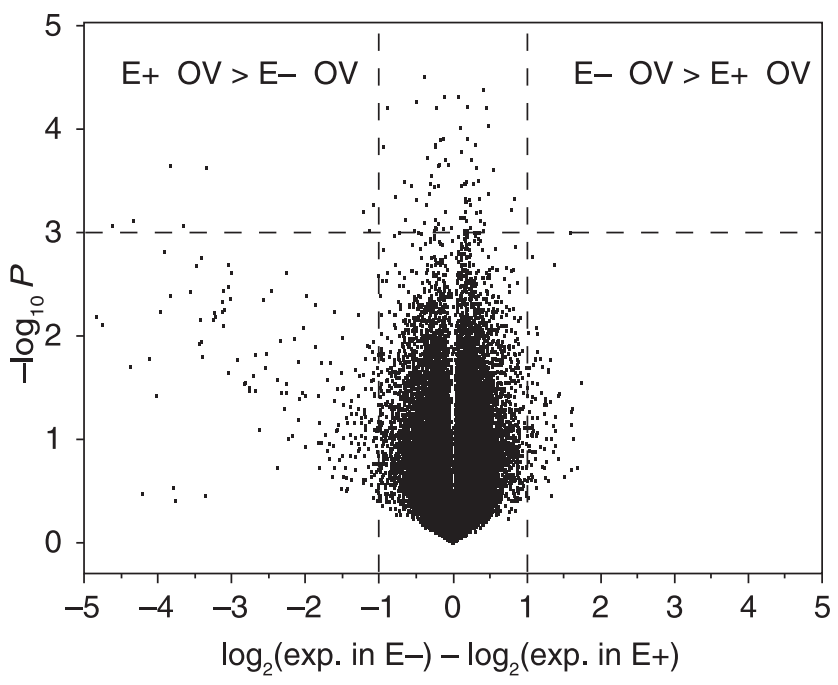

Fig. 7. Volcano plots comparing expression of plant genes between endophyte-symbiotic (E+) and endophyte free (E-) ovaries (OV) of tall fescue. Vertical dashed lines indicate the twofold cut-off for expression differences, and horizontal dashed lines indicate the minimum $P$ value for significance $=$ 0.001 . 
As with ROS, the important signaling functions of trehalose and T6P also must be considered (Iturriaga et al. 2009). Mutant studies in yeast and plants indicate regulatory roles of T6P in glycolysis and sugar metabolism. Furthermore, a T6P synthase mutant of $A$. thaliana (Eastmond et al. 2002) and a T6P phosphatase mutant of Zea mays (Satoh-Nagasawa et al. 2006) are affected in reproductive development. In A. thaliana, TPS1, one of the T6P synthases, is required for initiation of floral primordia (van Dijken et al. 2004). Given these roles in plant reproductive development, perhaps trehalose or T6P produced by E. coenophiala counteracts what would otherwise be negative effects of the endophyte on plant morphogenesis or carbohydrate metabolism during host reproductive development. Conceivably, trehalose produced by E. coenophiala also may help mitigate the apparent in symbio growth-inhibition effects of ROS (Tanaka et al. 2012).

In our plant transcriptome analysis, we investigated endophyte effects in the host OV by using four different pairs of tall fescue clones that differed only in endophyte presence $(E+)$ or absence $(\mathrm{E}-)$. We observed almost no plant DEGs in response to the endophyte (at $P \leq 0.001$ ). This finding is consistent with some of the past ultrastructural studies in natural grassEpichloe interactions, in which there is no evident response of the host to the endophyte (Koga et al. 1993; Philipson and Christey 1986). Also, in our previous study of tall fescue gene expression in vegetative tissues (leaf, PS, crown and root), in which we also compared E+ and E- clone pairs, very few plant genes were affected by the endophyte (Dinkins et al. 2017). Results of other studies of Epichlö̈ effects on plant transcriptomes contrast with ours and with each other. In Festuca rubra, SAGE analysis revealed 209 genes with expression significantly different in E+ versus E- plants, but almost all the expression differences were modest (Ambrose and Belanger 2012). In dramatic contrast, a study of $L$. perenne symbiosis with E. festucae Fl1 (Dupont et al. 2015) indicated significant endophyte effects on expression of $38 \%$ of host genes. Schmid et al. (2017) investigated $L$. perenne with a strain of its natural endophyte variety, E. festucae var. lolii Lp19, and results differed markedly from those of Dupont et al. (2015) in that more modest numbers and effects were observed on host gene expression and there was little relationship between the sets of DEGs. The different studies involved different levels of control on host genotypes, techniques of endophyte introduction, and timing of inoculation relative to RNA-seq analysis as well as differences in statistical approaches, so comparisons of the results should be considered tentative. Our current study of reproductive tissues and our previous study of vegetative tissues (Dinkins et al. 2017) comparing naturally E. coenophialasymbiotic tall fescue plants to their endophyte-cured clones, indicates that the endophyte need not cause major changes in host transcriptomes in order to maintain a stable symbiosis that is efficiently transmitted through seeds.

In summary, our results indicate that there is almost no effect of endophytic E. coenophiala at the level of plant gene transcription even in reproductive organs, whereas the endophyte exhibits dramatically different gene expression in the different plant parts, notably involving genes for alkaloid biosynthesis, protein chaperones, ROS-scavenging systems, and trehalose biosynthesis. We propose that, if these differences relate to relative amounts of meristematic and differentiating plant tissues in the different plant parts, increased chaperone gene expression may be associated with the more invasive or proliferative phases of fungal growth, and increased expression of ROS scavenging and stress response genes may modulate autoregulatory signals affecting hyphal growth patterns and rates. We are exploring approaches to test this proposal, for example, by mapping changes in expression of these genes at the cellular level and identifying key genes for control of colonization of plant reproductive parts and, ultimately, seed transmission.

\section{MATERIALS AND METHODS}

Plants.

Four different tall fescue cv. Kentucky 31 plants with symbiotic $E$. coenophiala constituted the four biological replicates. For analysis of endophyte effects on plant gene expression, E+ and E- clone pairs were generated as previously described (Nagabhyru et al. 2013). Briefly, ramets of each plant were treated with fungicide to generate E- clones, and the four pairs of $\mathrm{E}+$ and $\mathrm{E}$ - clones were propagated and divided as needed for more than one year in the greenhouse before beginning the study. The LP, PS, and OV as well as IP-s and IP-1 of the E+ clones were sampled to compare fungal gene expression between these plant parts. With each plant genotype representing a biological replicate, a total of $19 \mathrm{E}+$ samples (Table 1) as well as $\mathrm{E}-\mathrm{OV}$ from three plants were used for sequencing.

In addition to tall fescue, we also investigated gene expression by Brachypodium sylvaticum and its endophyte, Epichlö̈ sylvatica, in OV and PS. Seeds from the United States National Plant Germplasm System (NPGS) were germinated and seedlings were tested by immunoblot (An et al. 1993) for the presence or absence of E. sylvatica. An E+ B. sylvaticum plant from NPGS accession PI 610793 was designated plant 4929 and an E- plant from the same accession was designated plant 4930.

The plants were grown in the greenhouse in PROMIX-BX medium in $10-\mathrm{cm}$ diameter pots, with $16 \mathrm{~h}$ of light, $22^{\circ} \mathrm{C}$ day and $20^{\circ} \mathrm{C}$ night temperatures, and twice daily watering.

\section{Harvest and treatment of plant parts.}

Inflorescences from the four plants were all harvested at the same time when plants were at the flowering stage. Florets on tall fescue typically mature from the top of the inflorescence downward, so unopened florets can be identified within $24 \mathrm{~h}$ preceding anthesis. Such preanthesis florets were harvested for OV and LP isolation and were placed directly into RNAlater stabilization solution (Ambion, Thermo Fisher Scientific, Waltham, MA, U.S.A.), to prevent RNA degradation, and were incubated at $4^{\circ} \mathrm{C}$ for at least 2 days. Each floret was then dissected with fine forceps to gently remove $\mathrm{OV}$ and the surrounding bracts (LP), which were placed in RNAlater and stored at $-20^{\circ} \mathrm{C}$ until extracted.

All PS samples from the four plants were harvested at the same time, when they were primarily vegetative. The PS samples constituted the basal 2 to $3 \mathrm{~cm}$ of the whorl from the crown and were flash-frozen in liquid nitrogen immediately after harvest and were stored at $-80^{\circ} \mathrm{C}$ until RNA extraction.

IP were harvested, as reproductive tillers developed, by gently removing leaf sheaths to expose the IP, which was removed from the crown, was immediately placed into RNAlater, was incubated 2 days at $4{ }^{\circ} \mathrm{C}$, and was stored at $-20^{\circ} \mathrm{C}$ until extracted. The IPs were classified as smaller (IP-s) at 3 to $5 \mathrm{~mm}$ in length and larger (IP-1) at 7 to $12 \mathrm{~mm}$ in length.

To test whether use of RNAlater versus flash-freezing differentially affected transcript levels, we split the PS from each of four tillers from one plant, then, one half was treated and stored in RNAlater and the other half was flash-frozen and stored at $-80^{\circ} \mathrm{C}$. Reverse transcription-quantitative polymerase chain reaction analysis (Florea et al. 2016) was conducted with primers for nine endophyte genes (Supplementary Fig. S5) and using the endophyte translation elongation factor $1-\alpha$ gene as the reference. The results indicated no significant effect of the sample preparation and storage procedure on transcript levels (Supplementary Dataset S12). 


\section{RNA extraction and cDNA library preparation}

\section{for RNA-seq.}

Plant samples were gently removed from the RNAlater solution and RNA isolation was carried out using a Qiagen (Hilden, Germany) RNeasy plant mini kit per manufacturer instructions. The RNA was treated with the TURBO DNA-free kit (Ambion) to remove contaminating DNA. Quality and quantity of RNA was checked on an Agilent (Santa Clara, CA, U.S.A.) Bioanalyzer 2100 , using the plant RNA nano chip, and 3 to $4 \mu \mathrm{g}$ of high quality RNA (RNA integrity number $>8.0$ ) was used to isolate and purify mRNA, using oligo-dT beads, and for random hexamerprimed cDNA library preparation according to the Illumina (San Diego, CA, U.S.A.) TruSeq RNA sample preparation guide. The cDNA libraries were validated on the Agilent Technologies 2100 Bioanalyzer, using the DNA-specific chip DNA-1000, and libraries were sent to the Iowa State University DNA sequencing facility for sequencing on an Illumina HiSeq. The samples were barcoded (indexed with different sequence tags provided in the kit) and six samples were run in each lane of the flow cell. Information retrieved from the sequencing facility was analyzed using the CLC Genome Workbench (Qiagen).

\section{Analysis of mRNA data using CLC Bio and JMP Genomics.}

RNA-seq reads were processed using CLC Bio (version 8.5.1) of the CLC Genome Workbench. Reads were first trimmed to remove any adapter and low-quality sequences using the CLC Bio Trim tool. Then total reads were separated into plant and fungal reads as follows. First, we mapped the reads against the E. coenophiala e4163 genome (University of Kentucky Genome Projects database), using the CLC Bio RNA-seq analysis tool with the mapping settings set to minimum length fraction $=0.9$ and minimum similarity fraction $=0.95$. The threshold for a fungal gene call was 10 reads mapped to the model.

The unmapped 'potential plant reads' were used for further analysis of plant genes. For plant gene expression analysis, the reads from tall fescue samples were mapped against the tall fescue transcriptome assembly TF153K (Dinkins et al. 2017) by using mapping parameters set to minimum length fraction = 0.9 and minimum similarity fraction $=0.8$. The threshold for a plant gene call was 20 reads mapped to the model.

Analysis of differential expression employed CLC Bio Genomics Workbench and JMP Genomics (SAS Institute, Cary, NC, U.S.A.). Each sample was considered as a replicate and comparisons to the normalized values were across all treatments. Endophyte reads were normalized with the reads per million (RPM) protocol, whereas plant reads were normalized with the trimmed mean of $\mathrm{M}$ values protocol. The filtered and normalized data were processed for quality control using the JMP Basic RNA-seq workflow and were analyzed for data distribution, data correlation and group correlation. Analysis of variance compared RPM-corrected counts to determine twofold differences by a false discovery rate multiple testing method $(\alpha=0.1)$. Any fungal gene with a minimum of twofold difference in expression between plant parts and significant at $P \leq 0.01$ was considered a DEG.

For analysis of B. sylvaticum-E. sylvatica samples, the total reads obtained were mapped to the $B$. distachyon genome assembly in GenBank (GCF_000005505.1) to identify plant gene reads, and to the genome sequence of E. sylvatica GR 10156 (University of Kentucky Genome Projects database and GenBank Bioproject PRJNA275112) to identify fungal reads. Reads mapped to the genome sequences with CLC Bio were used for gene expression analysis in JMP Genomics.

\section{Pathway and GO term enrichment analysis.}

For pathway analysis of plant DEGs we ran the AgriGO analysis tool (Du et al. 2010) against the B. distachyon annotated gene models. For GO term enrichment analysis of fungal DEGs, we identified orthologous genes of $M$. robertsii ARSEF 23 and submitted the corresponding locus tag lists to the online FungiFun2 website (Priebe et al. 2015).

\section{DNA-seq for relative endophyte biomass estimation.}

To estimate relative endophyte biomass in each plant sample, DNA from PS, OV, and LP samples of the four E+ tall fescue plants was sequenced on the Illumina MiSeq platform. DNA was extracted with the Qiagen plant mini kit, and approximately $1 \mu \mathrm{g}$ of DNA was used to prepare each library with the Illumina TruSeq DNA sample preparation kit. Samples were barcoded with unique compatible indexes and were sequenced, 250 cycles each end, three samples per MiSeq chip.

Adapter sequences and low-quality reads were trimmed using trimmomatic and duplicate reads were filtered with the duplicate reads removal plug-in (version 0.3 beta 3 , Build: 120605-1523) in CLC Bio. Then, filtered reads from each sample were mapped to the genome sequence of E. coenophiala e19 (Florea et al. 2016) for the tall fescue-E. coenophialum system, thereby separating fungal DNA reads from total plant reads.

\section{ACKNOWLEDGMENTS}

The authors thank T. Boss and S. Holton for maintaining plants in the greenhouse and W. Hollin for technical support. The authors also thank J. Jaromczyk for help with the MiSeq data processing and assembly and N. Moore for genome sequence annotation and public release at the University of Kentucky Genome Projects database. The authors also acknowledge AGTC at the University of Kentucky and the Iowa DNA sequencing facility for providing sequencing services. This is publication number 18-12-047 of the Kentucky Agricultural Experiment Station, published with the approval of the director.

\section{LITERATURE CITED}

Ambrose, K. V., and Belanger, F. C. 2012. SOLiD-SAGE of endophyteinfected red fescue reveals numerous effects on host transcriptome and an abundance of highly expressed fungal secreted proteins. PLoS One 7: e53214.

An, Z. Q., Siegel, M. R., Hollin, W., Tsai, H.-F., Schmidt, D., and Schardl, C. L. 1993. Relationships among non-Acremonium sp. fungal endophytes in five grass species. Appl. Environ. Microbiol. 59:1540-1548.

Antonin, W., Wagner, M., Riedel, D., Brose, N., and Jahn, R. 2002. Loss of the zymogen granule protein syncollin affects pancreatic protein synthesis and transport but not secretion. Mol. Cell. Biol. 22:1545-1554.

Assuero, S. G., Tognetti, J. A., Colabelli, M. R., Agnusdei, M. G., Petroni, E. C., and Posse, M. A. 2006. Endophyte infection accelerates morphophysiological responses to water deficit in tall fescue. New Zeal. J. Agr. Res. 49:359-370.

Bacetty, A. A., Snook, M. E., Glenn, A. E., Noe, J. P., Hill, N., Culbreath, A., Timper, P., Nagabhyru, P., and Bacon, C. W. 2009. Toxicity of endophyteinfected tall fescue alkaloids and grass metabolites on Pratylenchus scribneri. Phytopathology 99:1336-1345.

Benaroudj, N., Lee, D. H., and Goldberg, A. L. 2001. Trehalose accumulation during cellular stress protects cells and cellular proteins from damage by oxygen radicals. J. Biol. Chem. 276:24261-24267.

Bouton, J. H., Latch, G. C. M., Hill, N. S., Hoveland, C. S., McCann, M. A., Watson, R. H., Parish, J. A., Hawkins, L. L., and Thompson, F. N. 2002. Reinfection of tall fescue cultivars with non-ergot alkaloid-producing endophytes. Agron. J. 94:567-574.

Cantarel, B. L., Korf, I., Robb, S. M. C., Parra, G., Ross, E., Moore, B., Holt, C., Sánchez Alvarado, A., and Yandell, M. 2008. MAKER: An easy-to-use annotation pipeline designed for emerging model organism genomes. Genome Res. 18:188-196.

Card, S. D., Tapper, B. A., Lloyd-West, C., and Wright, K. M. 2013. Assessment of fluorescein-based fluorescent dyes for tracing $\mathrm{NeO}$ typhodium endophytes in planta. Mycologia 105:221-229.

Cartwright, G. M., and Scott, B. 2013. Redox regulation of an AP-1-like transcription factor, YapA, in the fungal symbiont Epichloe festucae. Eukaryot. Cell 12:1335-1348.

Christensen, M. J., Bennett, R. J., Ansari, H. A., Koga, H., Johnson, R. D., Bryan, G. T., Simpson, W. R., Koolaard, J. P., Nickless, E. M., and 
Voisey, C. R. 2008. Epichloë endophytes grow by intercalary hyphal extension in elongating grass leaves. Fungal Genet. Biol. 45:84-93.

Chung, K.-R., and Schardl, C. L. 1997. Sexual cycle and horizontal transmission of the grass symbiont, Epichloë typhina. Mycol. Res. 101: 295-301.

Cohu, C. M., and Pilon, M. 2007. Regulation of superoxide dismutase expression by copper availability. Physiol. Plant. 129:747-755.

Culotta, V. C., Klomp, L. W. J., Strain, J., Casareno, R. L. B., Krems, B., and Gitlin, J. D. 1997. The copper chaperone for superoxide dismutase. J. Biol. Chem. 272:23469-23472.

Dinkins, R. D., Nagabhyru, P., Graham, M. A., Boykin, D., and Schardl, C. L. 2017. Transcriptome response of Lolium arundinaceum to its fungal endophyte Epichloë coenophiala. New Phytol. 213:324-337.

Du, Z., Zhou, X., Ling, Y., Zhang, Z., and Su, Z. 2010. agriGO: A GO analysis toolkit for the agricultural community. Nucleic Acids Res. 38: W64-W70.

Dupont, P.-Y., Eaton, C. J., Wargent, J. J., Fechtner, S., Solomon, P., Schmid, J., Day, R. C., Scott, B., and Cox, M. P. 2015. Fungal endophyte infection of ryegrass reprograms host metabolism and alters development. New Phytol. 208:1227-1240.

Eastmond, P. J., van Dijken, A. J. H., Spielman, M., Kerr, A., Tissier, A. F., Dickinson, H. G., Jones, J. D. G., Smeekens, S. C., and Graham, I. A. 2002. Trehalose-6-phosphate synthase 1, which catalyses the first step in trehalose synthesis, is essential for Arabidopsis embryo maturation. Plant J. 29:225-235.

Eaton, C. J., Dupont, P. Y., Solomon, P., Clayton, W., Scott, B., and Cox, M. P 2015. A core gene set describes the molecular basis of mutualism and antagonism in Epichloë spp. Mol. Plant-Microbe Interact 28:218-231.

Ekanayake, P. N., Hand, M. L., Spangenberg, G. C., Forster, J. W., and Guthridge, K. M. 2012. Genetic diversity and host specificity of fungal endophyte taxa in fescue pasture grasses. Crop Sci. 52:2243-2252.

Elbersen, H. W., and West, C. P. 1996. Growth and water relations of fieldgrown tall fescue as influenced by drought and endophyte. Grass Forage Sci. 51:333-342.

Elmi, A. A., and West, C. P. 1995. Endophyte infection effects on stomatal conductance, osmotic adjustment and drought recovery of tall fescue. New Phytol. 131:61-67.

Elmi, A. A., West, C. P., Robbins, R. T., and Kirkpatrick, T. L. 2000 Endophyte effects on reproduction of a root-knot nematode (Meloidogyne marylandi) and osmotic adjustment in tall fescue. Grass Forage Sci. 55:166-172.

Enright, A. J., Van Dongen, S., and Ouzounis, C. A. 2002. An efficient algorithm for large-scale detection of protein families. Nucleic Acids Res. 30:1575-1584.

Fang, Y., Fliss, A. E., Rao, J., and Caplan, A. J. 1998. SBA1 encodes a yeast hsp90 cochaperone that is homologous to vertebrate p23 proteins. Mol. Cell. Biol. 18:3727-3734.

Fath, A., Bethke, P. C., and Jones, R. L. 2001. Enzymes that scavenge reactive oxygen species are down-regulated prior to gibberellic acid-induced programmed cell death in barley aleurone. Plant Physiol. 126:156-166.

Florea, S., Panaccione, D. G., and Schardl, C. L. 2017. Ergot alkaloids of the family Clavicipitaceae. Phytopathology 107:504-518.

Florea, S., Phillips, T. D., Panaccione, D. G., Farman, M. L., and Schardl, C. L. 2016. Chromosome-end knockoff strategy to reshape alkaloid profiles of a fungal endophyte. G3 (Bethesda) 6:2601-2610.

Foster, A. J., Jenkinson, J. M., and Talbot, N. J. 2003. Trehalose synthesis and metabolism are required at different stages of plant infection by Magnaporthe grisea. EMBO J. 22:225-235.

Freeman, E. M. 1904. The seed fungus of Lolium temulentum L., the darnel. Philos. T. R. Soc. Lon. B 196:1-27.

Geisse, N. A., Wäsle, B., Saslowsky, D. E., Henderson, R. M., and Edwardson, J. M. 2002. Syncollin homo-oligomers associate with lipid bilayers in the form of doughnut-shaped structures. J. Membr. Biol. 189:83-92.

Harris, E. D. 1992. Copper as a cofactor and regulator of copper,zinc superoxide dismutase. J. Nutr. 122 (suppl_3):636-640.

Hinton, D. M., and Bacon, C. W. 1985. The distribution and ultrastructure of the endophyte of toxic tall fescue. Can. J. Bot. 63:36-42.

Hoveland, C. 2009. Origin and history. Pages 3-10 in: Tall Fescue for the Twenty-first Century. H. A. Fribourg, D. B. Hannaway, and C. P. West, eds. American Society of Agronomy, Crop Science Society of America, Soil Science Society of America, Madison, WI, U.S.A.

Hückelhoven, R. 2004. BAX Inhibitor-1, an ancient cell death suppressor in animals and plants with prokaryotic relatives. Apoptosis 9:299-307.

Hume, D. E., and Sewell, J. C. 2014. Agronomic advantages conferred by endophyte infection of perennial ryegrass (Lolium perenne $\mathrm{L}$.) and tall fescue (Festuca arundinacea Schreb.) in Australia. Crop Pasture Sci. 65:747-757.

Iordachescu, M., and Imai, R. 2008. Trehalose biosynthesis in response to abiotic stresses. J. Integr. Plant Biol. 50:1223-1229.
Iturriaga, G., Suárez, R., and Nova-Franco, B. 2009. Trehalose metabolism: From osmoprotection to signaling. Int. J. Mol. Sci. 10:3793-3810.

Johnson, L. J., Koulman, A., Christensen, M., Lane, G. A., Fraser, K., Forester, N., Johnson, R. D., Bryan, G. T., and Rasmussen, S. 2013. An extracellular siderophore is required to maintain the mutualistic interaction of Epichloë festucae with Lolium perenne. PLoS Pathog. 9:e1003332.

Johnson, R. D., Lane, G. A., Koulman, A., Cao, M., Fraser, K., Fleetwood, D. J., Voisey, C. R., Dyer, J. M., Pratt, J., Christensen, M., Simpson, W. R., Bryan, G. T., and Johnson, L. J. 2015. A novel family of cyclic oligopeptides derived from ribosomal peptide synthesis of an in planta-induced gene, gigA, in Epichloë endophytes of grasses. Fungal Genet. Biol. 85:14-24.

Karim, S., Aronsson, H., Ericson, H., Pirhonen, M., Leyman, B., Welin, B., Mäntylä, E., Palva, E. T., Van Dijck, P., and Holmström, K.-O. 2007. Improved drought tolerance without undesired side effects in transgenic plants producing trehalose. Plant Mol. Biol. 64:371-386.

Koga, H., Christensen, M. J., and Bennett, R. J. 1993. Incompatibility of some grass-Acremonium endophyte associations. Mycol. Res. 97:1237-1244.

Koulman, A., Lee, T. V., Fraser, K., Johnson, L., Arcus, V., Lott, J. S., Rasmussen, S., and Lane, G. 2012. Identification of extracellular siderophores and a related peptide from the endophytic fungus Epichloë festucae in culture and endophyte-infected Lolium perenne. Phytochemistry $75: 128-139$.

Kubota, H., Hynes, G., and Willison, K. 1995. The chaperonin containing tcomplex polypeptide 1 (TCP-1). Eur. J. Biochem. 230:3-16.

Leslie, S. B., Israeli, E., Lighthart, B., Crowe, J. H., and Crowe, L. M. 1995. Trehalose and sucrose protect both membranes and proteins in intact bacteria during drying. Appl. Environ. Microbiol. 61:3592-3597.

Liu, J., Nagabhyru, P., and Schardl, C. L. 2017. Epichloë festucae endophytic growth in florets, seeds, and seedlings of perennial ryegrass (Lolium perenne). Mycologia 109:691-700.

Lotz, G. P., Brychzy, A., Heinz, S., and Obermann, W. M. J. 2008. A novel HSP90 chaperone complex regulates intracellular vesicle transport. J. Cell Sci. 121:717-723.

Lu, H., Zhu, Z., Dong, L., Jia, X., Sun, X., Yan, L., Chai, Y., Jiang, Y., and Cao, Y. 2011. Lack of trehalose accelerates $\mathrm{H}_{2} \mathrm{O}_{2}$-induced Candida albicans apoptosis through regulating $\mathrm{Ca}^{2+}$ signaling pathway and caspase activity. PLoS One 6:e15808.

Lunn, J. E., Delorge, I., Figueroa, C. M., Van Dijck, P., and Stitt, M. 2014 Trehalose metabolism in plants. Plant J. 79:544-567.

Lyons, P. C., Evans, J. J., and Bacon, C. W. 1990. Effects of the fungal endophyte Acremonium coenophialum on nitrogen accumulation and metabolism in tall fescue. Plant Physiol. 92:726-732.

Magnard, J. L., Vergne, P., and Dumas, C. 1996. Complexity and genetic variability of heat-shock protein expression in isolated maize microspores. Plant Physiol. 111:1085-1096.

Majewska-Sawka, A., and Nakashima, H. 2004. Endophyte transmission via seeds of Lolium perenne L.: Immunodetection of fungal antigens. Fungal Genet. Biol. 41:534-541.

Malinowski, D. P., and Belesky, D. P. 1999. Neotyphodium coenophialumendophyte infection affects the ability of tall fescue to use sparingly available phosphorus. J. Plant Nutr. 22:835-853.

Malinowski, D. P., and Belesky, D. P. 2000. Adaptations of endophyteinfected cool-season grasses to environmental stresses: Mechanisms of drought and mineral stress tolerance. Crop Sci. 40:923-940.

Meyer, P., Prodromou, C., Liao, C., Hu, B., Mark Roe, S., Vaughan, C. K., Vlasic, I., Panaretou, B., Piper, P. W., and Pearl, L. H. 2004. Structural basis for recruitment of the ATPase activator Ahal to the Hsp90 chaperone machinery. EMBO J. 23:511-519.

Moon, C. D., Craven, K. D., Leuchtmann, A., Clement, S. L., and Schardl, C. L. 2004. Prevalence of interspecific hybrids amongst asexual fungal endophytes of grasses. Mol. Ecol. 13:1455-1467.

Nagabhyru, P., Dinkins, R.D., Wood, C.L., Bacon, C.W., and Schardl, C.L. 2013. Tall fescue endophyte effects on tolerance to water-deficit stress. BMC Plant Biol. 13:127.

Oddon, D. M., Diatloff, E., and Roberts, S. K. 2007. A CLC chloride channel plays an essential role in copper homeostasis in Aspergillus nidulans at increased extracellular copper concentrations. Biochim. Biophys. Acta 1768:2466-2477.

Pan, J., Bhardwaj, M., Nagabhyru, P., Grossman, R. B., and Schardl, C. L. 2014. Enzymes from fungal and plant origin required for chemical diversification of insecticidal loline alkaloids in grass-Epichloë symbiota. PLoS One 9:e115590.

Philipson, M. N., and Christey, M. C. 1986. The relationship of host and endophyte during flowering, seed formation, and germination of Lolium perenne. New Zeal. J. Bot. 24:125-134.

Priebe, S., Kreisel, C., Horn, F., Guthke, R., and Linde, J. 2015. FungiFun2: A comprehensive online resource for systematic analysis of gene lists from fungal species. Bioinformatics 31:445-446. 
Redillas, M. F. R., Park, S.-H., Lee, J., Kim, Y., Jeong, J., Jung, H., Bang, S., Hahn, T.-R., and Kim, J.-K. 2012. Accumulation of trehalose increases soluble sugar contents in rice plants conferring tolerance to drought and salt stress. Plant Biotechnol. Rep. 6:89-96.

Satoh-Nagasawa, N., Nagasawa, N., Malcomber, S., Sakai, H., and Jackson, D. 2006. A trehalose metabolic enzyme controls inflorescence architecture in maize. Nature 441:227-230.

Schardl, C. L., Florea, S., Pan, J., Nagabhyru, P., Bec, S., and Calie, P. J. 2013a. The epichloae: Alkaloid diversity and roles in symbiosis with grasses. Curr. Opin. Plant Biol. 16:480-488.

Schardl, C. L., Young, C. A., Hesse, U., Amyotte, S. G., Andreeva, K., Calie, P. J., Fleetwood, D. J., Haws, D. C., Moore, N., Oeser, B., Panaccione, D. G., Schweri, K. K., Voisey, C. R., Farman, M. L., Jaromczyk, J. W., Roe, B. A., O’Sullivan, D. M., Scott, B., Tudzynski, P., An, Z., Arnaoudova, E. G., Bullock, C. T., Charlton, N. D., Chen, L., Cox, M., Dinkins, R. D., Florea, S., Glenn, A. E., Gordon, A., Güldener, U., Harris, D. R., Hollin, W., Jaromczyk, J., Johnson, R. D., Khan, A. K., Leistner, E., Leuchtmann, A., Li, C., Liu, J., Liu, J., Liu, M., Mace, W., Machado, C., Nagabhyru, P., Pan, J., Schmid, J., Sugawara, K., Steiner, U., Takach, J. E., Tanaka, E., Webb, J. S., Wilson, E. V., Wiseman, J. L., Yoshida, R., and Zeng, Z. 2013c. Plantsymbiotic fungi as chemical engineers: Multi-genome analysis of the Clavicipitaceae reveals dynamics of alkaloid loci. PLoS Genet. 9:e1003323.

Schardl, C. L., Young, C. A., Pan, J., Florea, S., Takach, J. E., Panaccione, D. G., Farman, M. L., Webb, J. S., Jaromczyk, J., Charlton, N. D., Nagabhyru, P., Chen, L., Shi, C., and Leuchtmann, A. 2013b. Currencies of mutualisms: Sources of alkaloid genes in vertically transmitted epichloae. Toxins (Basel) 5:1064-1088.

Schmid, J., Day, R., Zhang, N., Dupont, P. Y., Cox, M. P., Schardl, C. L., Minards, N., Truglio, M., Moore, N., Harris, D. R., and Zhou, Y. 2017. Host tissue environment directs activities of an Epichlö endophyte, while it induces systemic hormone and defense responses in its native perennial ryegrass host. Mol. Plant-Microbe Interact 30:138-149.

Spiering, M. J., Moon, C. D., Wilkinson, H. H., and Schardl, C. L. 2005. Gene clusters for insecticidal loline alkaloids in the grass-endophytic fungus Neotyphodium uncinatum. Genetics 169:1403-1414.

Suárez, R., Wong, A., Ramírez, M., Barraza, A., Orozco, M. C., Cevallos, M. A., Lara, M., Hernández, G., and Iturriaga, G. 2008. Improvement of drought tolerance and grain yield in common bean by overexpressing trehalose-6phosphate synthase in rhizobia. Mol. Plant-Microbe Interact 21:958-966.

Sugawara, K., Ohkubo, H., Mikoshiba, Y., and Yamashita, M. 2004. Flowers for Neotyphodium endophytes detection: A new observation method using flowers of host grasses. Mycoscience 45:222-226.

Svanström, А., van Leeuwen, M. R., Dijksterhuis, J., and Melin, P. 2014. Trehalose synthesis in Aspergillus niger: Characterization of six homologous genes, all with conserved orthologs in related species. BMC Microbiol. 14:90.

Takemoto, D., Tanaka, A., and Scott, B. 2006. A p67Phox-like regulator is recruited to control hyphal branching in a fungal-grass mutualistic symbiosis. Plant Cell 18:2807-2821.

Tanaka, A., Takemoto, D., Chujo, T., and Scott, B. 2012. Fungal endophytes of grasses. Curr. Opin. Plant Biol. 15:462-468.
Tanaka, A., Takemoto, D., Hyon, G.-S., Park, P., and Scott, B. 2008. NoxA activation by the small GTPase RacA is required to maintain a mutualistic symbiotic association between Epichlö festucae and perennial ryegrass. Mol. Microbiol. 68:1165-1178.

Timper, P., Gates, R. N., and Bouton, J. H. 2005. Response of Pratylenchus spp. in tall fescue infected with different strains of the fungal endophyte Neotyphodium coenophialum. Nematology 7:105-110.

Tsai, H. F., Liu, J. S., Staben, C., Christensen, M. J., Latch, G. C., Siegel, M. R., and Schardl, C. L. 1994. Evolutionary diversification of fungal endophytes of tall fescue grass by hybridization with Epichloë species. Proc. Natl. Acad. Sci. U.S.A. 91:2542-2546.

van Dijken, A. J., Schluepmann, H., and Smeekens, S. C. M. 2004. Arabidopsis trehalose-6-phosphate synthase 1 is essential for normal vegetative growth and transition to flowering. Plant Physiol. 135: 969-977.

Verghese, J., Abrams, J., Wang, Y., and Morano, K. A. 2012. Biology of the heat shock response and protein chaperones: Budding yeast (Saccharomyces cerevisiae) as a model system. Microbiol. Mol. Biol. Rev. 76:115-158.

Viarengo, A., Burlando, B., Ceratto, N., and Panfoli, I. 2000. Antioxidant role of metallothioneins: A comparative overview. Cell Mol. Biol. Noisy-le-grand 46:407-417.

Wang, Y., Zhang, W. Z., Song, L. F., Zou, J. J., Su, Z., and Wu, W. H. 2008. Transcriptome analyses show changes in gene expression to accompany pollen germination and tube growth in Arabidopsis. Plant Physiol. 148: 1201-1211.

White, J. F., Jr., Morrow, A. C., Morgan-Jones, G., and Chambless, D. A. 1991. Endophyte-host associations in forage grasses. XIV. Primary stromata formation and seed transmission in Epichlö typhina: Developmental and regulatory aspects. Mycologia 83:72-81.

Young, C. A., Charlton, N. D., Takach, J. E., Swoboda, G. A., Trammell, M. A., Huhman, D. V., and Hopkins, A. A. 2014. Characterization of Epichlö coenophiala within the US: Are all tall fescue endophytes created equal? Front Chem. 2:95.

Zhang, N., Zhang, S., Borchert, S., Richardson, K., and Schmid, J. 2011. High levels of a fungal superoxide dismutase and increased concentration of a PR-10 plant protein in associations between the endophytic fungus Neotyphodium lolii and ryegrass. Mol. Plant-Microbe Interact 24: 984-992.

Zhang, W., Card, S. D., Mace, W. J., Christensen, M. J., McGill, C. R., and Matthew, C. 2017. Defining the pathways of symbiotic Epichlö colonization in grass embryos with confocal microscopy. Mycologia 109:153-161.

\section{AUTHOR-RECOMMENDED INTERNET RESOURCES}

AgriGO analysis tool: bioinfo.cau.edu.cn/agriGO

FungiFun2 website: https://elbe.hki-jena.de/fungifun/fungifun.php

University of Kentucky Genome Projects database:

www.endophyte.uky.edu 